Canadian

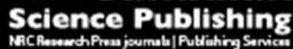

Canadian Geotechnical Journal Revue canadienne de géotechnique

\title{
Prediction and analysis of surface settlement due to shield tunneling for Xi'an Metro
}

\begin{tabular}{|r|l|}
\hline Journal: & Canadian Geotechnical Journal \\
\hline Manuscript ID & cgj-2016-0166.R2 \\
\hline Danuscript Type: & Article \\
\hline Complete List of Authors: & $\begin{array}{l}\text { Zhu, Caihui; State Key Laboratory Base of Eco-Hydraulic Engineering in } \\
\text { Arid Areas; Institute of Geotechnical Engineering } \\
\text { Li, Ning; Institute of Geotechnical Engineering }\end{array}$ \\
\hline Keyword: & $\begin{array}{l}\text { surface settlement, gap parameter, shield tunneling, analytical solution, } \\
\text { Xi'an Metro }\end{array}$ \\
\hline \multicolumn{2}{|c}{} \\
\hline
\end{tabular}




\title{
Prediction and analysis of surface settlement due to shield tunneling for Xi'an Metro
}

\author{
Caihui $\mathrm{ZHU}^{1,2,3,{ }^{*}}$, Ning $\mathrm{LI}^{1,2,3}$ \\ ${ }^{1}$ State Key Laboratory Base of Eco-Hydraulic Engineering in Arid Areas, Xi'an University \\ of Technology, Xi'an, China.
}

${ }^{2}$ D.E., Institute of Geotechnical Engineering, Xi'an University of Technology, 5 South Jinhua Road, Xi'an, Shaanxi, 710048, P.R. China.

${ }^{3}$ Shaanxi provincial key laboratory of loess mechanics, Xi'an University of Technology, Xi'an, China.

* Corresponding author: at State Key Laboratory Base of Eco-Hydraulic Engineering in Arid Areas, Xi'an University of Technology, Xi'an, 710048, P.R. China (Caihui ZHU)

E-mail addresses: zhucaihui123@163.com (Caihui ZHU)

Tel.: +86029 83293863; fax: +8602983293863.

2 Institute of Geotechnical Engineering, Xi'an University of Technology, Shaanxi, 710048, P.R. China. (Ning LI)

Email addresses: ningli@xaut.edu.cn (Ning LI)

Tel.: +86 029 83293863; fax: +8602983293863. 


\section{Prediction and analysis of surface settlement due to shield tunneling for Xi'an Metro}

Abstract: This study describes a new modified prediction method of surface settlement (SS) for Xi'an Metro. The estimation method of SS and its characteristic parameters, volume loss (VL), maximal SS and settlement trough width (STW) are reviewed and discussed in this paper. The gap parameter (GP) is applied to estimate VL, however, the calculation method of GP and its influence factors have not been clarified entirely. In this study, six influence factors are introduced into the new GP model and the detailed solutions are presented. This estimation method is able to take into account the support pressure of the shield head at the tunnel face, the lining support pressure around the tunnel opening, the filling effect of tail grouting, yawing and pitching of the shielding machine and the long-term deformation of the remoulded surrounding soil. Based on Xi'an Metro line 2, the soil behaviors and measured SS characteristics are deeply investigated. The upper and lower bounds of the total GP of the 15 cases are predicted. Comparison of the predicted SS troughs with field observations can show reasonable agreement. It is suggested that the new estimation method can be used effectively in estimating the SS induced by shield tunneling method.

Key words: surface settlement, shield tunneling, gap parameter, volume loss, analytical solution, Xi'an Metro. 


\section{Introduction}

\section{Researches on SS due to tunnelling}

Experience has shown that SS invariably occurs above shallow tunnels constructed in loess region. It is important to predict and control over the SS induced by the tunneling construction, which may cause damage to adjacent structures. Empirical and analytical methods (Peck 1969; Lo et al. 1984b; Lee 1989; Verruijt and Booker 1996; Loganathan and Poulos 1998; Hsieh and Ou 1998; Gonzales and Sagaseta 2001; Park 2005; Zhang et al. 2009; Chen et al. 2011), numerical methods (Karakus and Fowell 2003; Kasper and Meschke 2004; Hamid and Bahtiyar 2014; Ibrahim 2014; Shen and Xu 2011; Shen et al. 2013, 2014, 2016; Wu et al. 2015a, 2015b), and artificial intelligence methods (Melis et al. 2002; Suwansawat and Einstein 2006; Neaupane and Adhikari 2006; Pourtaghi and Lotfollahi 2012) have been widely used to estimate the SS due to tunneling. More recently Dindarloo and Siami-Irdemoosa (2015) have proposed the decision trees to predict SS. Saeid and Elnaz (2015) have presented a shallow tunnel classification system (STCS) to predict the maximal SS in soft grounds in urban areas. The validity of numerical method relies on the rationality of soil constitutive model and acquisition method of soil parameters. The applicability of empirical and artificial intelligence methods depends on a large amount of measurements, details of the soil stratum, tunneling techniques and engineering managements. For estimating the SS, the analytical method may be the most flexible way to achieve. It is now well known that, there are three important parameters of settlement troughs, which are the $\operatorname{STW}(i)$, maximal SS $\left(S_{\max }\right)$ and $\operatorname{VL}\left(V_{1}\right)$. Volume Loss $\left(V_{1}\right)$ is defined as the ratio of SS trough area $\left(S_{\mathrm{A}}\right)$ to excavation area $\left(S_{\mathrm{D}}\right)$ of the per unit length of tunnel. The STW $(i)$ is the 
horizontal distance between the point of inflection of the tunnel axial line, which is shown in Figure 1. Once the settlement characteristic parameters mentioned above are determined, the SS can be estimated easily.

In a word, for estimating the VL and maximal SS, many influence factors should be taken into consideration, and the GP can be exactly used to express the relations directly. On the basis of the GP concept, Lo et al. (1984b), Verruijt and Booker (1996), Chou and Bobet (2002), Park (2005) have respectively established their analytic formula to predict the SS. However, the parameter of workmanship in the GP is calculated with finite element method and local experiences, on the other hand, the influence factors of GP are not entirely clarified. It is important to present the new modeling of GP for estimating the SS.

In general, the GP is difficult to determine because of the complex influences of tunneling construction details and soil variations (Hamid and Bahtiyar 2014). The surrounding soil behaviors and the measured SS features will be deeply discussed based on Xi'an Metro line 2, Shannxi, China, and the new estimation method of GP is presented and discussed in this work. To assess the validity and limitations of the proposed method, SS behavior has been quantified for the 15 monitoring sections along Xi'an Metro Line 2. The estimations and measured results of the SS are compared with each other, with the conclusion obtained.

\section{SS prediction methods}

The STW $(i)$ is the horizontal distance between the point of inflection of the settlement trough and tunnel centreline. Several studies have reported that the STW is almost related to the buried depth $(H)$ and diameter $(D)$ of the tunnel in different types of soil strata. 
Supposing that the coefficient of STW $(k=i / H)$ is the ratio of STW $(i)$ to the buried depth of tunnel center $(H)$. Based on the published works by Han (2006), the empirical expressions and their application conditions are summarized in Table 1, with the coefficient of STW $k=0.20-0.28$ in the sandy soil, and $k=0.38-0.58$ in the clayed soil. The results indicate that the STW grows with an increase in the shear strength of the soil. However, it almost depends on the empirical experience rather than the theoretical arithmetic. In this study, a new estimating formula is presented on the basis of 15 historical cases.

Maximal SS $\left(S_{\max }\right)$ is the most important characteristic parameter of settlement trough, and it is concerned with the surrounding soil behaviors, tunneling methods and the assisting construction measures on the soil stratum. There are many methods to predict it, such as analytical methods (Gonzales and Sagaseta 2001; Verruijt and Booker 1996; Loganathan and Poulos 1998; Chou and Bobet 2002; Park 2004, 2005; Oteo and Moya 1979), empirical methods (Chen et al. 2011 and Dindarloo and Siami-Irdemoosa 2015). Table 2 indicates that $S_{\max }$ is inversely correlated with $H / D$.

Most of the analytical equations are used under undrained conditions. However, the long-term deformation of the remoulded surrounding soil due to excavation disturbance and construction technologies are not taken into consideration in the analytical and empirical methods. Shen et al. (2011, 2013, 2014, 2016) and Wu et al. (2015a, 2015b) have proposed numerical evaluation methods of land subsidence induced by groundwater pumping, and then the numerical methods are widely used to predict the long-term settlement because of shield tunneling, nearby construction, groundwater infiltration, cyclic loading of trains and urbanisation. The model simulates the measured value fairly well in soft clay in Shanghai. 
However, the above proposed numerical methods may not fit for the loess stratum (unsaturated soil) in Xi'an Metro. In addition, the maximal SS can be calculated indirectly with the VL proposed by Peck method (1969).

$$
S_{\max }=\frac{V_{l} \pi R^{2}}{\sqrt{2 \pi i}}
$$

Where $i$ is the SS trough width, $R$ is the outer radius of the shield cutter $(R=D / 2, D$ is the diameter of the shield cutter), $V_{1}$ is the volume loss.

The VL is related to convergence displacements of the tunnel opening and the tunnel diameter. The VL is concerned with the tunneling techniques and the soil behaviors, and it is almost obtained through measurements or local experiences. O'Reilly and New (1982), and Han (2006) have reported the empirical values of VL and provided the convenience for the SS prediction, with the results shown in Table 3.

These values indicate that VL decreases with an increase in the shear stiffness of tunnel surrounding soil. Minh Ngan Vu et al (2016) presented the analytical method of the total VL, which is influenced by the applied support pressures at the tunneling face, overcutting and shield shape along the shield, applied grouting pressure at the tail and soil consolidation behind the shield tail. The VL and maximal SS can be easily estimated with this method.

Based on the GP theory put forward by Rowe and Kack (1983), the VL can also be calculated using the following equation:

$$
V_{l}=\frac{4 g R+g^{2}}{4 R^{2}}
$$

where $g$ is the GP. Rowe and Kack (1983) used it to calculate the crown vertical deformation of the tunnels in undrained clays, with three dimensional elastoplastic 
deformation at the tunnel face, the effect of the workmanship of the shield tunneling and the physical gap or the geometry of the shield and lining system included. And they are equivalent to a two dimensional gap as shown in Figure 2.

\section{Xi'an Metro project and SS monitoring}

\section{Description of shield tunneling}

A 26.8-km subway was constructed in different soil layers in Xi'an, China. A full-face earth pressure balance (EPB) shield tunneling machine was used in the construction of the section between the Bell Tower station and South Gate station as shown in Figure 3, and the tunnel was supported by a bolted, precast, segmented, reinforced concrete lining with the following dimensions: the excavation diameter $D=6.16 \mathrm{~m}$, the diameter of the outer skin of the lining $D_{1}=6.0 \mathrm{~m}$, and the length of the shield $L=8.68 \mathrm{~m}$. The buried depth of the tunnel axis $H$ varied from 12.6 to $22.4 \mathrm{~m}$.

\section{Surrounding soil behaviors}

As is shown in Figure 4, the tunnel is located in silty clay deposits and old loess. The soils surrounding upper part of the tunnel comprise the mixed fill, soft saturated loess and new loess, while the soils surrounding lower part of the tunnel comprise mostly sandy soil. The groundwater line is about $6-10 \mathrm{~m}$ above the tunnel crown. The physical and mechanical parameters of surrounding soil matrix are primarily derived from laboratory-based triaxial compressibility experiments. Table 4 shows the laboratory test results of soil behaviors near the Bell Tower station $(13+290-13+734)$ and the South Gate station $(13+782-14+310)$, respectively. The particle size distributions of the different soil layers are presented in Figure 5, and the weight percentage of particle size less than $0.075 \mathrm{~mm}$ is more than $50 \%$. Table 4 
describes that the plastic index $\left(I_{\mathrm{p}}\right)$ is between 10 and 17, which indicates that the surrounding soil property is silty clay.

For estimating the SS, the soil mechanical parameters must be clearly clarified. The elastic modulus and Poisson's ratio are difficult to determine because of the influence of stress paths, drainage conditions and test methods. The undrained elastic modulus $\left(E_{\mathrm{u}}\right)$, deformation modulus $\left(E_{0}\right)$, and compression modulus $\left(E_{\mathrm{s}}\right)$ are often used incorrectly in certain numerical analysis. According to soil mechanics theory, the relationship between $E_{0}$ and $E_{\mathrm{s}}$ is written as:

$$
E_{0}=E_{s}\left(1-\frac{2 v^{2}}{1-v}\right)
$$

Where, $E_{0}$ is obtained from the plate load test; $E_{\mathrm{s}}$ is obtained from the laboratory consolidation test. $E_{\mathrm{u}}$ is obtained from the triaxial compression tests under undrained condition, and $v$ is the Poisson's ratio.

It can be seen from the above equation that $E_{0} \leq E_{\mathrm{s}}$ is in theory. However, Liu (1997) reported that, in reality, $E_{0}$ is 2.0-5.0 times larger than $E_{\mathrm{s}}$. He suggested that the relationship between $E_{0}$ and $E_{\mathrm{s}}$ should be a function of the initial void ratio $\left(e_{0}\right)$ in loess stratum:

$$
E_{0}=\frac{2.718 E_{s}}{e_{0}}
$$

According to elastic theory, the relationship between the undrained elastic modulus $E_{\mathrm{u}}$ and the partially drained elastic modulus $E_{0}$ can be expressed as:

$$
\frac{E_{u}}{E_{0}}=\frac{1+v_{u}}{1+v_{0}}
$$

Therefore, by combining (8) and (9), the undrained elastic modulus can be written as:

$$
E_{u}=\frac{2.718 E_{s}\left(1+v_{u}\right)}{\left(1+v_{0}\right) e_{0}}
$$


where, $v_{\mathrm{u}}=0.5$ is the undrained Poisson's ratio, and $v_{0}$ is the drained Poisson's ratio. In loess stratum, $v_{0}$ can be estimated using $v_{0}=K_{0} /\left(1+K_{0}\right)$, where $K_{0}$ is the coefficient of lateral stress at rest (and is equal to 1.0 under undrained conditions).

Many empirical formulae with $K_{0}$ relating to the effective friction angle $\left(\varphi^{\prime}\right)$ are studied. The details of $K_{0}$ under drained condition are summarized by Hu (1997) as listed in Table 5. Based on the laboratory tests and the engineering experiences, the weighted average of physical and mechanics parameters of the soils above the tunnel in 15 monitoring sections can be gained as shown in Table 6. The parameters can be used to estimate the GP and the SS.

\section{SS monitoring}

There are 15 equipped monitoring sections between the Bell Tower and South Gate stations in the right line of subway Line 2 as the Figure 3 shows. The Bell Tower is located between $13+353$ and $13+389$, and the South Gate of the City Wall is located between $14+200$ and 14+344. The horizontal monitoring sections for SS are installed in the topsoil below the pavement as shown in Figure 6(a) and (b), and the data are monitored with electronic digital level. To protect the Bell Tower, rotary drilling bored piles $(28.0 \mathrm{~m}$ long and $1.0 \mathrm{~m}$ in diameter, spaced at intervals of $1.3 \mathrm{~m}$ ) are pre-installed $8.0 \mathrm{~m}$ away from the ancient structure's boundary. The SS is monitored while the shield advances $30 \mathrm{~m}$ away from the structure's boundary, and it stops until the SS tends to be stable. The measured data are obtained by Zhang (2011). The SS troughs for the above monitoring sections are shown in Figure 7.

\section{SS case histories}

The EPB shield method is firstly introduced into Xi'an Metro Line 2. There has been a 
lack of engineering experience related to design and construction as well as SS control technology. Therefore, SS behaviors induced by shield tunneling should be thoroughly studied.

\section{SS characteristics determination}

\section{Volume loss}

The volume loss can be approximately estimated with the trapezoidal integration method on the basis of the measurements. If the number of measured data of SS is $n$, the SS trough is expressed as $S(\mathrm{x})$, then the SS trough area $\left(S_{\mathrm{A}}\right)$ can be divided into $(n-1)$ trapezoidal parts and the height of any trapezoid may be equally divided into $(b-a) /(n-1)$. Therefore, $\mathrm{S}_{\mathrm{A}}$ can be calculated:

$$
S_{A}=\int_{a}^{b} S(x) d x=\frac{b-a}{n-1}\left(\frac{S_{0}}{2}+S_{1}+S_{2}+\ldots+S_{n-1}+\frac{S_{n}}{2}\right)
$$

The VL $\left(V_{1}\right)$ can be expressed as follows:

$$
V_{l}=\frac{S_{A}}{S_{D}}=\frac{4(b-a)}{(n-1) \pi D^{2}}\left(\frac{S_{0}}{2}+S_{1}+S_{2}+\ldots+S_{n-1}+\frac{S_{n}}{2}\right) \ldots
$$

Where, $D$ is the tunnel excavation diameter, $a$ and $b$ are the horizontal distances from the tunnel center, and $S_{0}, S_{\mathrm{i}} \ldots S_{\mathrm{n}}$ are the SS values.

\section{Settlement trough width}

The Peck formula (1969) is expressed as follows:

$$
S_{x}=S_{\max } \exp \left[-\frac{x^{2}}{2 i^{2}}\right]
$$

where $x$ is horizontal displacement from the tunnel center, $i$ is the STW, $S_{\mathrm{x}}$ is the SS at a given monitoring point, and $S_{\max }$ is the maximum SS above the tunnel center. Supposing that the above equation can be simplified as a linear function: 


$$
Y=A+B X
$$

Where,

$$
Y=\operatorname{lnS}(x), X=-\frac{x^{2}}{2}, A=\ln \mathrm{S}_{\max }, B=\frac{1}{i^{2}}
$$

The best estimate value of $A$ and $B$ with least square method is presented as follows:

$$
\begin{aligned}
A & =\frac{\left(\sum X_{i}^{2}\right)\left(\sum Y_{i}\right)-\left(\sum X_{i}\right)\left(\sum X_{i} Y_{i}\right)}{n\left(\sum X_{i}^{2}\right)-\left(\sum X_{i}\right)^{2}} \\
B & =\frac{n\left(\sum X_{i} Y_{i}\right)-\left(\sum X_{i}\right)\left(\sum Y_{i}\right)}{n\left(\sum X_{i}^{2}\right)-\left(\sum X_{i}\right)^{2}}
\end{aligned}
$$

Where,

$$
Y_{i}=\operatorname{lnS}\left(x_{i}\right), X_{i}=-\frac{x_{i}^{2}}{2}
$$

$x_{\mathrm{i}}$ is the sample point, which is equal to the horizontal distance between the monitoring points and the tunnel axis; $S\left(x_{\mathrm{i}}\right)$ is the settlement value of the sample point $x_{\mathrm{i}} ; n$ is the amount of the sample points; $A$ and $B$ are the intercept and slope of the linear equation as Eq.(10), respectively.

Therefore the STW and maximal SS are expressed as follows:

$$
i=\frac{1}{\sqrt{B}}, \mathrm{~S}_{\max }=\operatorname{EXP}(A)
$$

\section{Case studies}

The SS measurements are shown in Figure 7, the STW (i) can be deduced with linear regression least square method, and $V_{1}$ can be calculated by using trapezoidal integration method. The variations of settlement characteristic parameter can be obtained, with the results shown in Table 7. The results reveal that:

(1)The average coefficient STW $(k=0.58)$ near the ancient structures (the Bell Tower and 
the City Wall $)$ is much higher than that of the ground $(k=0.37)$. However, maximal settlement value near the City Wall $\left(S_{\max }=-4.5\right.$ to $\left.-6.0 \mathrm{~mm}\right)$ is lower than that of the ground $\left(S_{\max }=\right.$ -11.8 to $-46.7 \mathrm{~mm}$ ). It indicates that the coefficient of STW broadens and settlement decreases due to the constraint imposed by the foundation of adjacent structures. By using the least square method, the following equations can be used to estimate the STW in Xi'an Metro:

$$
i=0.55 H+0.4
$$

It can be seen from Figure 8(a) that the proposed equation is much more suited to predict the surface STW of Xi'an Metro than others.

(2)The VL varies between $0.5 \%$ and $4.4 \%$, with an average loss of $1.69 \%$. These values are much higher than the empirical results $(0.22-0.75 \%)$ reported by Han (2006). According to Eq.(2), the GP can be given:

$$
g=2 R\left[\sqrt{1+V_{l}}-1\right]
$$

The relationship $g$ versus $S_{\max }$ can also be determined. As for the relationship between SS and tunnel crown deformation, Atkinson and Potts(1977) presented the following expression:

$$
\frac{S_{\max }}{u_{c}}=\left[1-\alpha\left(\frac{H-R}{2 R}\right)\right]
$$

Where $u_{\mathrm{c}}$ is vertical deformation at the tunnel crown (which is equal to the $g$ ), and $\alpha$ is the empirical parameter ( $\alpha=0.4$ for dense sands; $\alpha=0.13$ for normally to lightly consolidated clays).

A similar estimation equation is proposed by Clough and Schmidt(1981) as follows:

$$
\frac{S_{\max }}{u_{c}}=\left(\frac{2 R}{H}\right)^{\beta}
$$


where $\beta$ is the empirical coefficient, equal to 0.8 when the surrounding soil is clayed soil.

The comparison of $S_{\max } / g$ versus $H / D$ curves of different soil types are shown in Figure 8(b). This evaluation reveals that the method presented by Atkinson and Potts (1977) is not suitable for estimating the relationships among $S_{\max }, g$ and $H / D$ when $\alpha=0.4$ and $\alpha=0.13$, though it yields acceptable estimations when $\alpha=0.23$ in loess stratum presented by authors. The method presented by Clough and Schmidt(1981) may be much better when the empirical coefficient $\beta$ has the value of 0.9 . The main reason is that the surrounding soil is under consolidated loess and silty clay, which is very different from the sandy soil and normally consolidated clay.

(3)The relationship between measured maximal SS and the GP can be expressed by a linear equation. Based on 15 case studies conducted in stiff clay environments, Lo et al. (1984b) reported that the relationship between $S_{\max }$ and $g$ can be expressed as follows:

$$
S_{\max }=-0.33 g
$$

$\mathrm{Ng}$ et al. (1986) presented a similar expression based on a finite element analysis of the Thunder Bay tunnel:

$$
S_{\max }=-0.42 g
$$

Actually there is a linear relationship between $S_{\max }$ and $g$ that only occurs in an undrained clay soil. In a sand, the relationship will not be linear just as there will be volumetric contraction and dilation occurring in different zones above the tunnel at different levels of deformation. In this work, the loess is a kind of clay soil under undrained condition, the comparison of measured data with the different estimations is shown in Figure 8(c). In 
fact, the relationship between $\mathrm{S}_{\max }$ and $g$ can be calculated in the following for the loess strata:

$$
S_{\max }=-0.4146 g
$$

The above GP is gained by back analyzing of the measured results, however, it is important to estimate it in preliminary design stage. Thus the details pertaining to shield construction technology, as well as the tunnel surrounding soil behavior must be clarified. The new estimation of GP will be presented in the following sections.

\section{New estimation model of the GP}

\section{Definition and discussion on GP}

Based on the definition of the GP ( $g$ ) proposed by Lo and Rowe (1982), an equation to calculate the parameter was presented by Lo et al. (1984b). The term $(g)$ was divided into four components by Lee and Rowe (1992) as follows:

$$
g=G_{\mathrm{p}}+U_{3 D}^{*}+\omega+\omega_{1}
$$

where $g$ is the gap parameter. These components include the three-dimensional elasto-plastic deformation at the tunnel face, the effect of the quality of workmanship with respect to shield tunnel construction, the physical gap $\left(G_{\mathrm{p}}\right)$, and the reconsolidation or creep of the remoulded soil. These four factors are considered equivalent to a two-dimensional gap, which are illustrated in Figure 2. In Eq.(22), $G_{\mathrm{p}}$ refers to the geometric clearance between the outer skin of the shield and lining, and it is equal to $2 \Delta+\delta$. Where, $\Delta$ is the thickness of the tailpiece of the shield machine, and $\delta$ is the clearance required for the erection of lining. For shields with an overcutter, the physical gap increases with the size of the overcut. $G_{\mathrm{p}}$ is determined when the shield machine and the lining system are chosen. If grouting is effectively injected into the tailpiece voids, $G_{\mathrm{p}}$ tends to approach zero. However, in soft clays 
$G_{\mathrm{p}}$ is reduced to $7-10 \%$ of the theoretical physical gap reported by Loganathan and Poulos (1998). Still with respect to Eq.(22), $U_{3 D}^{*}$ represents the equivalent three-dimensional elasto-plastic deformation ahead the tunneling face, which is induced by the removal of the in situ stress ahead of the tunneling face. $U^{*}{ }_{3 D}$ can be written as follows:

$$
U_{3 D}^{*}=\frac{\Omega R\left(K_{0}^{\prime} P_{V}^{\prime}+P_{w}-P_{i}\right)}{2 E_{u}}
$$

where $\Omega$ is a dimensionless value representing axial displacement ahead of the tunneling face. $\Omega$ has a value of 1.12 when the stability number $N \leq 2.5$ for all variables considered, according to the 3D finite element analysis presented by Lee (1989). However, $\Omega$ increases rapidly when $N \geq 3.0$.

$P_{\mathrm{v}}^{\prime}$ is the effective vertical stress at the tunnel axis, $P_{\mathrm{w}}$ is the pore pressure at the tunnel axis, and $P_{\mathrm{i}}$ is the tunnel supporting pressure between the tunnel face and the shield head. If the tunnel is fully excavated, the value of $P_{\mathrm{i}}$ is 0 ; if there is compressed air at the tunneling face, or pressure at the shield face, then $P_{\mathrm{i}}>0 . \omega_{1}$ represents the degree of crown displacement due to re-consolidation of the remoulded zone. This parameter is important for the calculation of long-term SS.

The component $\omega$ is necessitated by the pitching, yawing, intermittent alignment and steering problems that can occur depending on the tunneling machine, the effectiveness of tail void grouting, the rate of soil deformation and human error. In estimating process of the workmanship parameter $\omega$, there are three influence factors that need to be considered:

1) In the event of upward or downward shield pitching, additional soil around the tunnel will be overcut, resulting in a loss of ground. The workmanship parameter $\omega$ can be expressed as follows: 
$\omega=L \times($ excess pitch $)$

where $L$ is the length of shield. The "excess pitch" parameter is determined by the shield steering engineers based on a comparison with the relative location of shield axis.

2) In addition to shield pitching, shield machine yawing may occur. In that case the surrounding soil will be over-excavated due to irregular side-to-side motion of the tunneling machine, but, it is not discussed in Eq.(22).

3) With respect to intermittent shield alignment and steering problems, the workmanship parameter $\omega$ may be the minimum value between $0.6 G_{\mathrm{p}}$ and $U_{\mathrm{i}} / 3$, where $U_{i}$ is the radial tunnel crown displacement. For elasto-plastic conditions ( $N>1$ and $K_{0}=1.0$ ), the plane strain solution of $U_{i}$ is just as proposed by Lo et al. (1984b):

$$
\frac{U_{i}}{R}=1-\sqrt{\left\{\frac{1}{1+\frac{2\left(1+v_{u}\right) c_{u}}{E_{u}}\left[\exp \left(\frac{N-1}{2}\right)\right]^{2}}\right\}}
$$

where $P_{0}$ is the effective hydrostatic overburden pressure at the tunnel face, $P_{\mathrm{i}}$ is the tunnel support pressure between lining and surrounding soil, $E_{\mathrm{u}}, c_{\mathrm{u}}$ and $v_{\mathrm{u}}$ are elastic modulus, shear strength and Poisson's ratio under undrained conditions, respectively, and $N$ is the stability number of the tunnel face. $N$ is defined as follows: $N=\left(\gamma H-P_{\mathrm{i}}\right) / c_{\mathrm{u}}$.

In this section, the GP that can arise due to various influence factors has been reviewed and discussed. However, some of these methods mentioned above may not be suitable for Xi'an Metro contexts, such as the drainage condition, initial stress condition and the 
mechanical behaviors of tunnel surrounding soil. The new GP models are presented and modified in the next section.

\section{Gap induced by inadequate shield support pressure}

For application of the EPB method, the support pressure $\left(P_{\mathrm{i}}\right)$ of shield must be dynamically consistent with the lateral earth pressure $\left(P_{0}\right)$ of soil stratum. SS will occur when $P_{\mathrm{i}}$ is less than $K_{0} P_{0}$. Otherwise, ground uplift occurs. In the light of traditional limit equilibrium theory, the relationship between the earth pressure balance of shield and surface movement behavior can be described as shown in Figure 9.

According to the theory suggested by Lo et al. (1984b) and Lee and Rowe (1992), when there is an imbalance with respect to support pressure $\left(P_{\mathrm{i}}\right)$, the first component of GP $\left(g_{1}\right)$ can be approximated by:

$$
g_{1}=U_{3 D}^{*}=\frac{\Omega R\left(K_{0}^{\prime} P_{V}^{\prime}+P_{w}-P_{i}\right)}{2 E_{u}}
$$

Leca and Dormieux (1990) viewed that the lower and upper bounds of support pressure value in collapse and blowout conditions can be calculated using weighting and surcharge coefficients ( $N_{\gamma}$ and $N_{\mathrm{s}}$, respectively):

$$
P_{i}=N_{s} \sigma_{s}+2 N_{\gamma} \gamma R
$$

where $\sigma_{\mathrm{s}}$ is ground surface surcharge.

(1) For the lower bound of the support pressure value, the weighting coefficient $N_{\gamma}$ can be expressed as:

$$
N_{\gamma}^{c-}=\tan ^{2}\left(\frac{\pi}{4}-\frac{\varphi^{\prime}}{2}\right)\left(\frac{H+R}{2 R}\right), N_{\gamma}^{b-}=\tan ^{2}\left(\frac{\pi}{4}+\frac{\varphi^{\prime}}{2}\right)\left(\frac{H-R}{2 R}\right)
$$

where $N_{\gamma}{ }^{\mathrm{c}-}$ is the weighting coefficient under collapse conditions, and $N_{\gamma}^{\mathrm{b}-}$ is the 
weighting coefficient under blowout conditions.

(2) For the upper bound of the support pressure value, the weighting coefficients $\left(N_{\gamma}{ }^{\mathrm{c}+}\right.$ and $\left.N_{\gamma}^{\mathrm{b}+}\right)$ are related to the angle between failure surface and horizontal $\left(\delta^{\mathrm{c}+}=\right.$ $49^{\circ}+\varphi^{\prime} / 2$ in the event of a collapse, and $\delta^{\mathrm{b}+}=49^{\circ}-\varphi^{\prime}$ in the event of a blowout, where $\varphi^{\prime}$ is the effective friction angle). The weighting coefficients with respect to the upper bound should be checked against the results proposed by Leca and Dormieux (1990)

When calculating the GP $\left(g_{1}=U_{3 \mathrm{D}} *\right)$ that arises from inadequate support pressure, the additional pressure at the tunnel face between shield head and soil should be derived first. However, it is complicated to estimate it with analytical or empirical methods, but it can be real-timely investigated by the monitoring equipment of the shield machine.

Measurements are taken at the 15 monitoring sites along the length of Xi'an Metro provided that this support pressure value of $P_{\mathrm{i}}$ varies from 0.15 to $0.25 \mathrm{MPa}$, and the other parameters are shown in Table 4. The calculation with Eq.(28) demonstrates that the stability number $N=3.5-5.6$, and the gap $g_{1}=1.1-10.3 \mathrm{~mm}$.

\section{Effect of grouting elimination on the physical gap}

Theoretically, shield tail grouting should completely be filled into the physical gap to prevent SS caused by ground VL. However, it is difficult to determine the extent to which the grouting fills the gap because of irregular grouting, grouting losses during transport, unstable grouting pressure, grouting volume decreases, and grouting hardening and so on.

Suppose that the effective fill rate of grouting into the shield tail or physical gap is $\varpi$. After that the thickness of unfilled gap (the second component of GP $g_{2}$ ) at the tunnel crown 
can be deduced as follows:

$$
g_{2}=(1-\varpi) G_{\mathrm{p}}
$$

Based on measurements of Xi'an Metro Line 2, the backfill grouting loss ratio at the shield tail is between $5 \%$ and $10 \%$. Therefore, the fill ratio of grouting $(\varpi)$ is between $90 \%$ and $95 \%$. Loganathan and Poulos. (1998) demonstrated that the grouting loss ratio was generally between $7 \%$ and $10 \%$. Accordingly, the residual gap is $g_{2}$. In the case of the construction of Xi'an Metro, the physical gap $\left(G_{\mathrm{p}}=160 \mathrm{~mm}\right)$ is well-filled by tail grouting, leaving a small residual gap $g_{2}=8 \mathrm{~mm}$ to $16 \mathrm{~mm}$. If the grouting pressure is much higher than the vertical stress value, or if excessive grouting is injected into the physical gap and intrude into the surrounding soil, the stratum concerned will heave rather than subside.

\section{Gap due to intermittent shield alignment}

The ground VL due to intermittent shield alignment could be estimated according to the 3D elastic or elasto-plastic numerical analysis results (Lee,1989), therefore, the third component of GP can be calculated as follows:

$$
g_{3}=(\text { correction factor }) \times R\left[1-\sqrt{\frac{1+\frac{2\left(1+v_{\mathrm{u}}\right) c_{\mathrm{u}}}{E_{\mathrm{u}}}\left[\exp \left(\frac{P_{0}-P_{i}-c_{\mathrm{u}}}{2 c_{\mathrm{u}}}\right)\right]^{2}}{2}}\right] .
$$

where $E_{\mathrm{u}}, v_{\mathrm{u}}$ and $c_{\mathrm{u}}$ are the undrained elastic modulus, Poisson's ratio and shear strength, respectively. $P_{0}$ is the initial vertical overburden stress at the tunnel axis and $P_{\mathrm{i}}$ is the support pressure between the surrounding soil and the tunnel lining. For the elastic case, the correction factor is $1 / 3$, whereas for the elasto-plastic case, the correction factor is approximately $1 / 4$.

Nevertheless, these semi-analytical and semi-numerical approximations are only relevant 
to uniform initial stress or undrained conditions (i.e. $K_{0}=1.0, v_{\mathrm{u}}=0.5$ ) and may not be appropriate when tunneling is undertaken under more complex initial stress conditions (i.e. $K_{0}$ $\left.\neq 1.0, v_{\mathrm{u}}<0.5\right)$. The degree of radial crown displacement under general conditions can be obtained on the basis of the Lame and Kiersch equation.

Figure 10 shows that SS occurs when the internal supporting pressure $\left(P_{\mathrm{i}}\right)$ is less than the initial vertical stress $\left(P_{\mathrm{v}}\right)$. When it is not the case, the ground surface heaves instead of subsiding.

Based on the uniform stress field solution proposed by Lame and the single direction stress field solution proposed by Kiersch, the nonuniform stress field solution with respect to tunnel crown deformation can be obtained by overlapping these results. The Lame and Kiersch solution is well known in the fields of elastic and elasto-plastic mechanics. The tunnel crown deformation can be derived according to the principles outlined in the following.

When the actual internal support pressure $P_{\mathrm{i}}$ is equal to or less than the critical internal pressure $P_{\text {ic }}$, a plastic zone is generated in the soil around the tunnel during excavation. $P_{\text {ic }}$ is calculated as follows:

$$
P_{i c}=(1-\sin \varphi)\left[\frac{P_{0}}{2}\left(3 K_{0}-1\right)+\frac{c}{\tan \varphi}\right]-\frac{c}{\tan \varphi}
$$

1) If $P_{\mathrm{i}}>P_{\mathrm{ic}}$, then the soil around the tunnel is in an elastic state. The elastic tunnel crown deformation $U_{\mathrm{e}}$ is expressed as:

$$
U_{e}=\frac{(1+v) R}{2 E}\left[\left(1+K_{0}\right) P_{0}+\left(1-K_{0}\right)(3-4 v) P_{0}-2 P_{i}\right]
$$

2) If $P_{\mathrm{i}}<P_{\mathrm{ic}}$, then the soil around the tunnel is in an elasto-plastic state. The elasto-plastic tunnel crown deformation $U_{\mathrm{ep}}$ is computed as: 


$$
U_{e, p}=\frac{(1+v)}{2 E} \frac{R_{0}^{\left(\frac{2}{1-\sin \psi}\right)}}{R^{\left(\frac{1+\sin \psi}{1-\sin \psi}\right)}}\left[\left(1+K_{0}\right) P_{0}+\left(1-K_{0}\right)(3-4 v) P_{0}-2 P_{i}\right]=U_{e}\left(\frac{R_{0}}{R}\right)^{\left(\frac{2}{1-\sin \psi}\right)}
$$

where $\psi$ is the dilatancy angle, and $\mathrm{R}_{0}$ is the radius of the plastic zone. When the plastic volume change is zero, $\psi=0$ ), when the associate behavior is considered, $\psi=\varphi$. In this study, the dilatancy angle of clayey soil is zero, $R_{0}$ is calculated as follows:

$$
R_{0}=R\left\{\frac{(1-\sin \phi)\left[0.5\left(1+K_{0}\right) P_{0}-\left(1-K_{0}\right) P_{0}+c / \tan \phi\right]}{P_{i}+c / \tan \phi}\right\}
$$

Where, $c$ represents the degree of cohesion and $\varphi$ is the internal friction angle of the soil surrounding the tunnel.

Yet, according to actual field measurements recorded during a tunnel engineering exercise in a loess environment, Liu (1997) asserted that the measured internal support pressure between the lining and the soil surrounding the tunnel is $0.25-0.5$ times the vertical pressure $(P)$, which is determined in terms of arch theory, and can be converted into the following:

$$
P=\frac{\gamma R[1+\tan (\pi / 4-\varphi / 2)]}{\tan \varphi}
$$

The internal support pressure $P_{\mathrm{i}}$ is thus estimated as follows:

$$
P_{i}=(0.25-0.50) P
$$

Based on the results reported by Lee and Rowe (1992), the gap due to shield steering problems is equal to the lower out of $0.6 G_{\mathrm{p}}$ and $U_{\mathrm{i}} / 3$. Therefore, the gap $\left(g_{3}\right)$ due to inadequate internal support pressure can be formulated as follows: 


$$
g_{3}=\min \left(\left\{\begin{array}{ll}
\frac{1}{3} U_{e} & \left(\text { if } P_{i}>P_{i c}\right) \\
\frac{1}{4} U_{e, p} & \left(\text { if } P_{i}<P_{i c}\right)
\end{array}, 0.6 g_{2}\right)\right.
$$

Under general stress conditions (i.e. when $\left.K_{0} \neq 1.0\right)$, the critical internal pressure $\left(P_{\text {ic }}\right)$ and the internal supporting pressure $\left(P_{\mathrm{i}}\right)$ reflecting the interface pressure between the lining and the surrounding soil should be compared. Then the extent of the plastic zone can be determined to allow for the derivation of the elastic $\left(U_{\mathrm{e}}\right)$ or the elasto-plastic $\left(U_{\mathrm{e}, \mathrm{p}}\right)$ crown deformation parameter. It should be emphasized that this GP $\left(g_{3}\right)$ is derived according to the semi-analytical and semi-numerical analysis results reported by Lee and Rowe (1992) as shown in Table 8. These results are much lower than those derived by the general stress formula. The former figures range from 1.2 to $1.6 \mathrm{~mm}$, while the latter range from 4.8 to 9.6 $\mathrm{mm}$. Provided that there are no shield steering problems during construction work, the term $g_{3}$ should be equal to zero.

\section{Gap due to shield yawing}

Because of the heterogeneity of soil strata and difficulties encountered during shield machine driving, shield yawing occurs easily. The shield axis is often not consistent with the design grade of the tunnel. When this is the case, over-excavation occurs and SS (or VL) ensues. The yawing value of a shield head, $\delta_{0}$, can be measured on the shield equipment itself (which is illustrated in Figure 11) and is introduced as follows:

$$
\delta_{0}=\kappa L=L \tan \alpha
$$

where $L$ is the length of the shield machine (for this study the value is $8.68 \mathrm{~m}$ ), $\alpha$ is the yawing angle, and $\kappa$ is the shield yawing ratio.

The degree of over-excavation per meter $S_{\mathrm{e}}$ can be calculated as follows: 


$$
S_{\mathrm{e}}=\left(\pi-2 \theta_{0}\right) R^{2}+\delta_{0} R \sin \theta_{0}=\pi\left(R^{\prime 2}-R^{2}\right)
$$

where:

$$
\cos \left(\theta_{0}\right)=\delta_{0} / 2 R=\kappa L / 2 R
$$

$\theta_{0}$ is the yawing angle of the main body of the machine.

According to the definition of VL proposed by Rowe and Kack (1983), the ground VL $V_{1}$ due to over-excavation can be described as:

$$
V_{l}=\frac{V_{e}}{V_{s}}=\frac{S_{\mathrm{e}}}{\pi R^{2}}=\frac{\left(\pi-2 \theta_{0}\right) R^{2}+\kappa L R \sin \theta_{0}}{\pi R^{2}}=\frac{4 g R+g^{2}}{4 R^{2}}
$$

Though solving Eq.(41), the fourth component of GP $\left(g_{4}\right)$ induced by shield over-excavation can be written as:

$$
g_{4}=2\left(\sqrt{2 R^{2}\left(1-\frac{1}{\pi} \arccos \frac{\kappa L}{2 R}\right)+\frac{\kappa L}{2 \pi} \sqrt{4 R^{2}-\kappa^{2} L^{2}}}-R\right)
$$

If the shield advances with good alignment, shield yawing and pitching will not occur. However, with respect to this particular study, the shield is steered in a downward sloping curve between the $13+290$ and $13+460$ stations (see Figure 4). Thus, overcutting problems are likely to have occurred. In Xi'an Metro Line 2, the shield yawing ratio $\kappa$ is \pm 0.5 to $\pm 2.0 \%$, and the GP $g_{4}$ is $2.8-11.0 \mathrm{~mm}$.

\section{Gap due to shield pitching}

According to Lee and Rowe (1992), the workmanship parameter $\left(g_{5}\right)$ due to upward and downward shield pitching can be calculated as follows:

$$
g_{5}=L \times(\text { excess pitch })+m \times(\text { thickness of the beads })
$$

where $m=0$ means that there is no bead in the shield, $m=1$ means that the bead spans across the upper semicircle of the hood, and $m=2$ means that there is a full circle of beads in 
the hood.

In the case of Xi'an Metro, the excess shield pitch is controlled within $\pm 3 \%$, and the fifth component of GP $\left(g_{5}\right)$ induced by pitching is about $25 \mathrm{~mm}$ wide with no bead in the hood. While the shield is equipped to accommodate two beads to allow for curvilinear advancement, the beads are generally not used.

\section{Gap due to long term $\mathrm{VL}$}

The above mentioned VL or GP factors have occurred during tunneling operations. But, delayed soil movements induced by long term consolidation and creep processes can occur in the tunnel surrounding soil for a long time after tunneling operations are completed. These long term soil losses arise due to the following three causes:

(1) The first potential cause is the drainage of underground water and subsequent soil creep if the tunnel is unlined or unsupported at the tunnel face, beyond that, the other cause of long-term soil loss is the seepage of lining. This process may be partially stemmed if the EPB method is employed, impermeable support lining is installed, and grouting is injected into the tail void. The degree of consolidation and creep deformation at the tunnel crown can be estimated using a one-dimensional model.

(2) The second potential cause of long term soil loss around shield tunnels is the softening of the surrounding soil caused by water loss from the tail void grouting if the soil matrix is unsaturated. It is difficult to control over grouting pressure and the flow directions of grouting materials in the non-uniform surrounding soil matrix. The surrounding soil will be wetted by seepage through the grouting in response to the matric suction of the unsaturated soil matrix surrounding the tunnel. However, this 
effect can be avoided if the surrounding soil is beneath the ground water table. The softening and deformation of soils surrounding tunnels is complex. The process described in this paragraph depends on the saturation degree of soil matrix, as well as soil-water characteristics and can be analyzed according to the principles of unsaturated consolidation theory.

(3) The third potential cause of long term soil loss in the vicinity of tunnels is the reconsolidation of the remoulded surrounding soil matrix as a result of the advancement of shield. In loess strata, the frictional forces between the outer skin of shield and surrounding soil can cause the longitudinal tensile stresses, which can subsequently result in the development of a plastic zone, and it ultimately leads to soil failure and the flow of soil material into the annulus when the tailpiece clears the lining. The tunnel crown reconsolidation deformation $\left(g_{6}\right)$ of the plastic region can be calculated according to one-dimensional consolidation theory:

$g_{6}=m_{v}^{\prime} \Delta \sigma^{\prime}\left(R_{0}-R\right)$

where $m_{\mathrm{v}}{ }^{\prime}$ is the coefficient of volume compressibility of the remoulded surrounding soil. It is hard to test the in situ mechanical behavior of remoulded soil under complex loading conditions (unloading, reloading and shear). However, through laboratory experimentation using samples of remoulded soil collected in the field, it is found that the volume compressibility coefficient of remoulded soil is three or five times higher than that of undisturbed soil (Table 6). $R_{0}$ is the radius of the plastic region and $R$ is the tunnel opening radius. $\Delta \sigma^{\prime}$ is the average variation of effective stress in the plastic region, which is the difference between the initial stress and the 
residual stress after the tunnel has been excavated and lined. Under undrained conditions, the variation of effective stress is equal to the total stress. The average initial vertical stress $\left(\sigma_{1}\right)$ in the plastic region can be calculated as follows:

$\sigma_{1}=\frac{\gamma\left(H-R_{0}\right)+\gamma(H-R)}{2}$

The average residual stress $\left(\sigma_{2}\right)$ in the plastic region can be obtained using the

formulae presented by Lame and Kiersch:

$\sigma_{2}=\frac{\left(P_{i}+c / \tan \varphi\right)\left(R_{0} / R\right)^{\frac{2 \sin \varphi}{1-\sin \varphi}}-c / \tan \varphi+P_{i}}{2}$

or

$$
\sigma_{2}=\frac{\gamma\left(R_{0}-R\right)}{2}+P_{i}
$$

where $P_{\mathrm{i}}$ is defined as:

$$
P_{i}=(0.25-0.50) \frac{\gamma R[1+\tan (\pi / 4-\varphi / 2)]}{\tan \varphi}
$$

Then, the average variation of effective stress $\Delta \sigma^{\prime}$ before and after construction in the plastic region can be expressed as:

$$
\Delta \sigma^{\prime}=\left|\sigma_{1}-\sigma_{2}\right|
$$

Therefore, the sixth component of GP induced by the reconsolidation of remoulded soil in the plastic region can be written as:

$$
g_{6}=m_{v}^{\prime}\left[\gamma\left(H-R_{0}\right)-P_{i}\right]\left(R_{0}-R\right)
$$

The plastic deformation of the remoulded soil surrounding the tunnel applies only to the plastic zone. Consequently, the gap $\left(g_{6}\right)$ is equal to the vertical reconsolidation of the plastic zone, and the ratio of the plastic zone to radius $R_{0} / R$ has a range of $0.83-1.42$. It can be 
deduced that the depth of the plastic zone varies between 0.0 and $0.59 \mathrm{~m}$, and the crown reconsolidation of the plastic zone varies from 0.0 to $81.3 \mathrm{~mm}$.

\section{Application}

\section{Combined effect of gap parameter}

Combining all of the various potential influences on the GP, a composite GP can be expressed using the following equation:

$$
g_{t}=\sum_{1}^{6} g_{i}
$$

where $g_{\mathrm{t}}$ represents the composite effect of all the component of $g_{\mathrm{i}}$ discussed above. All the components of the GP are summarized in Table 9. It shows that there have been an upper bound and a lower bound in the components of GP because of the uncertainty of the shield control technology. Thus, the average value of the above GP component in the ordinary shield interval (without adjacent structures) is suggested in this study, which can be estimated as follows:

$$
g_{\text {tav }}=\sum_{i=1}^{6}\left(\frac{g_{i l}+g_{i u}}{2}\right)
$$

Where, the term $g_{\text {tav }}$ is the average value of the GP; $g_{\text {il }}$ stands for the lower bound component of the GP; $\mathrm{g}_{\mathrm{iu}}$ stands for the upper bound component of the GP.

In general, an assessment of the influence factors mentioned above includes six aspects. The procedure for estimating the GP components can be summarized as follows:

(1) If the support pressure at the tunnel face is caused by the EPB shield advancing, then the stability number $N$ may be small and the VL induced by inadequate support pressure may be low or tend toward zero. Therefore, the gap tends to be zero. During 
the initial design stages of a tunneling project, when calculating the shield support pressure at the tunnel face in contexts where the soil matrix comprises soft, saturated loess and/or non-cohesive soils, the methods proposed by Leca and Dormieux (1990) can be carefully used.

(2) Currently, the physical gap $\left(G_{\mathrm{p}}\right)$ will be almost completely filled with tail grouting, while the residual gap $g_{2}$ will only be $0.05-0.10 G_{\mathrm{p}}$.

(3) The gap $\left(g_{3}\right)$ arising from shield machine steering problems should be modified, whereby depending on initial general stress conditions. These conditions along with a measure of the internal support pressure between the surrounding soil and lining may be the critical influence factors for $g_{3}$. However, the elastic or elasto-plastic deformation of tunnel crown should be clarified. To this end, the critical internal support pressure $P_{\text {ic }}$ should be calculated first and compared with the actual internal support pressure $P_{\mathrm{i}}$.

(4) The gap arising from yawing $\left(g_{4}\right)$ and pitching $\left(g_{5}\right)$ of the shielding machine should be estimated in view of the machine's measurements. Whether this gap appears or not depends largely on the shield design grades and the excellence of the workmanship during shield tunneling.

(5) The gap $\left(g_{6}\right)$ caused by long-term deformation of surrounding soil can be easily overlooked because of its small size in stiff clay environments, where surrounding soils are soft and/or saturated, the processes of reconsolidation and creep should not be ignored.

(6) If the shield passes through under the adjacent buildings, the controlling technologies 
of the shield advancing and assisting construction measures must be adopted to the ground. Thus the total GP should be estimated with the lower bound $\left(g_{t 1}\right)$ as shown in

\section{Table 9.}

Based on the above components of the GP, each of which is subject to certain influence factors, the estimated range of the composite GP $\left(g_{\mathrm{t}}\right)$ for the 15 monitoring sections along Xi'an Metro line 2 can be obtained as shown in Table 9. Results show that the predicted lower bounds of GP change from 16.7 to $104.6 \mathrm{~mm}$, while the upper bounds vary from 57.9 to 145.8 $\mathrm{mm}$. The actual measured GP ranges from 15.3 to $134.0 \mathrm{~mm}$. It can be concluded that the modified GP estimation method proposed in this study is suitable for the prediction of the GP and the SS behavior induced by shield tunneling.

\section{SS prediction}

\section{Modified Peck method}

According to the GP estimation equations presented above, the SS trough can be estimated in the following equation:

$$
S_{x}=g_{t}[1-0.23(H / D-0.5)] \exp \left[-\frac{x^{2}}{2(0.55 H+0.4)^{2}}\right]
$$

where the term $g_{\mathrm{t}}$ is derived from Eq. (51); $g_{\mathrm{t}}=g_{\mathrm{tav}}$ when the shield passes through the ordinary shield intervals; $g_{\mathrm{t}}=g_{\mathrm{tl}}$ when the shield advances adjacent the structures; $g_{\mathrm{t}}=g_{\mathrm{tu}}$ when the shield passes through the saturated loess; STW $i$ can be calculated using Eq. (15).

Based on the new presented estimation method of the GP, the SS troughs can be estimated with Eq. (53), and compared with the measured data as shown in Figure 12. It shows that the estimations are in good agreement with measured results with a few exceptions. It can also be concluded that the lower bound estimation method is to fit for predicting the SS 
due to tunneling in the soil with higher shear strength, and the upper bound estimation method is suitable for the soil with lower shear strength.

The difference between the estimates and measured values completely depends on the geotechnical behavior of the surrounding soil and on the shield tunneling technology employed at a particular site. The main reason may be concluded as following:

(1)At some tunnel intervals passing through the beneath of the ancient buildings, the tunnel surrounding soils are reinforced by bored piles, so that, the remoulded and reinforced soil parameters are not consistent with the undisturbed soil.

(2)The upper and lower bounds of the shield advancing parameters such as grouting, yawing, pitching and intermittent shield alignment are also to change a lot in different sections.

In general, the more accurately the GP influence factors can be estimated, the more precise the overall GP prediction will be. However, it is difficult for engineers to precisely synthesize all of the potential influence factors. The method presented in this paper can prove helpful in the prediction of SS and the selection of optimal shield advancement technology.

\section{Conclusions}

On account of the existing theory, the various causes of ground VL arising from shield tunneling in loess have been revisited and modified by the inclusion of a GP. The factors affecting this parameter have been quantitatively estimated using various calculation methods. The comparison is made of the SS estimations results with the SS measured results is conducted, and the conclusion can be drawn as follows:

(1)The new presented gap factor can be separated into six main sub-parameters, namely 
the shield supporting pressure at the tunnel face $\left(g_{1}\right)$, the grouting effect $\left(g_{2}\right)$, the internal supporting pressure between the surrounding soil and the lining $\left(g_{3}\right)$, the yawing and pitching of the shielding machine $\left(g_{4}\right.$ and $\left.g_{5}\right)$, and the long-term VL of the remoulded surrounding soil $\left(g_{6}\right)$. All the components of GP have a range of variation because of the control limits of the shield tunneling technology.

(2)The SS can be estimated based on the upper and lower bounds of the presented GP $\left(g_{\mathrm{t}}\right)$. The average GP ( $\left.g_{\text {tav }}\right)$ may be properly used in the ordinary shield intervals without influence of adjacent buildings, however, when the shield advances adjacent the structures, the assisting reinforcement measures of the soil foundation may be conducted, and the lower bound of the GP $\left(g_{\mathrm{tl}}\right)$ should be carefully considered for fear that the over estimation of the SS will occur. The lower bound estimation method is to fit for predicting the SS due to tunneling in the soil with higher shear strength, and the upper bound estimation method is suitable for the soil with lower shear strength.

(3) The surface settlement can be estimated on the basis of the Gaussian curve. The VL $\left(V_{1}\right)$ and maximal SS $\left(S_{\max }\right)$ can be obtained indirectly by using the new presented estimation method of the total GP. The STW $(i)$ can be determined by the empirical regression equations.

(4)This work has focused on clarifying the short-term influence factors with respect to the GP, and especially on supporting pressure (i.e. the interface effect of soil-shield head and the soil-lining systems) and shield deflection (i.e. intermittent alignment and steering problems, and machine yawing and pitching). In addition, the long 
term factors influencing the GP are also presented using the Lame and Kiersch formulae. Soil consolidation and creep owing to the drainage of underground water and the softening of unsaturated surrounding soil as a result of water loss from the tail void grouting also require consideration, but they are beyond the scope of this paper.

\section{Acknowledgments}

The research described in this paper is financially supported by National Natural Science Foundation of China (NSFC) through Grant No. 51308456 and No. 51678484. This support is gratefully acknowledged. This article is also supported by Project of Scientific Research of Shaanxi (Grant No. 2015JM5175) and the Postdoctoral fund of Shaanxi province(2014) and Shaanxi provincial key laboratory of loess mechanics (16JS073) and State Key Laboratory Base of Eco-Hydraulic Engineering in Arid Areas, and are also gratefully acknowledged. The authors acknowledge thoughtful and helpful comments from the reviewers. 


\section{References}

Atkinson, J.H., and Potts, D.M. 1977. Stability of a shallow circular tunnel in cohesionless soil. Géotechnique, 27 (2), 203-215.

Chakeri, H., and Ünver, B. 2014. A new equation for estimating the maximum surface settlement above tunnels excavated in soft ground, Environmental Earth Sciences, 71(7), 3195-3210.

Chen, R.P., Zhu, J., Liu, W., and Tang, X.W. 2011. Ground movement induced by parallel EPB tunnels in silty soils. Tunn. Undergr. Space Technol. 26 (1), 163-171.

Chou, W-I., and Bobet, A. 2002. Predictions of ground deformations in shallow tunnels in clay, Tunnelling and Underground Space Technology, 17, 3-19.

Clough, G.W., and Schmidt, B. 1981. Design and performance of excavations and tunnels in soft clay. In Soft Clay Engineering, Elsevier. 569-634.

Dindarloo, S.R., and Siami-Irdemoosa, E. 2015. Maximum surface settlement based classification of shallow tunnels in soft ground, Tunnelling and Underground Space Technology, 49, 320-327. (DOI: 10.1016/j.tust.2015.04.021).

Gonzales C, and Sagaseta, C. 2001. Patterns of soil deformations around tunnels. Application to the extension of Madrid Metro. Comput. Geotech , 28, 445-68.

Han, X.. 2006. The Analysis and Prediction of Tunnelling-induced Building Deformation. Ph. D. Thesis, Xi'an: Xi'an University of Technology. (in Chinese)

Hsieh, P.-G., and Ou, C.-Y. 1998. Shape of ground surface settlement profiles caused by excavation. Can. Geotech. J. 35 (6), 1004-1017.

Hu, Z-X. 1997. Soil mechanics and environmental geotechnique. Shang hai: Tongji University Press. (in Chinese)

Karakus, M., and Fowell, R.J. 2003. Effects of different tunnel face advance excavation on the settlement by FEM. Tunn. Undergr. Space Technol. 18 (5), 513-523. 
Kasper, T., and Meschke, G. 2004. A 3D finite element simulation model for TBM tunnelling in soft ground. Int. J. Numer. Anal. Meth. Geomech. 28 (14), 1441- 1460.

Leca, E., and Dormieux, L. 1990. Upper and lower bound solutions for the face stability of shallow circular tunnels in frictional material. Geotechnique, 40(4), 581-606.

Lee, K.M., and Rowe, R.K. 1992. Subsidence due to tunnelling: Part II -Evaluation of a prediction technique. Canadian Geotechnical Journal. 29(5), 941-954.

Lee, K-M. 1989. Prediction of ground deformations resulting from shield tunnelling in soft clays (volumes I And II).

Liu, Z. 1997. Mechanics and engineering of loess. Xi'an: Shanxi science and technique publishing house. (in Chinese)

Lo, K,Y., Ng, M.C., and Rowe, R.K. 1984b. Predicting settlement due to tunneling in clays, ASCE, Geotech Conference, Atlanta, GA, 46-76.

Lo, K.Y., and Rowe, R.K. 1982. Prediction of ground subsidence due to tunneling in clays, Research report GEOT 10-82, the University of Western Ontario, London, Ontario, Canada.

Loganathan, N., and Poulos, H.G. 1998. Analytical prediction for tunneling-induced ground movements in clays. Jnl. Geot. And Geoenv. Eng., ASCE, 124(9), 846-856.

Melis, M., Medina, L., and Rodriguez, J.M. 2002. Prediction and analysis of subsidence induced by shield tunnelling in the Madrid Metro extension. Can. Geotech. J. 39 (6), $1273-1287$.

Neaupane, K.M., and Adhikari, N.R. 2006. Prediction of tunneling-induced ground movement with the multi-layer perceptron. Int J Tunneling and Underground Space Technol, 21, $151-159$.

Ng, R.M.C., Lo, K.Y., and. Rowe, R.K. 1986. Analysis of field performance - the Thunder Bay tunnel, Can. Geotech. J. ,23, 30-50 
Ogawa, T. 1986. Elasto-plastic, thermo-mechanical and three dimensional problems in tunneling, Ph.D. Thesis, the University of Western Ontario, London, Ontario, Canada.

O'Reilly, M.P., and New, B.M. 1982. Settlements above tunnels in the United Kingdom-their magnitude and prediction. Proc. Tunnelling 82, Institution of Mining and Metallurgy, London, 173-181.

Oteo, C., and Moya, J.F. 1979. Evaluación de parámetros del suelo de Madrid con relación a la construcción de túneles. In Proceedings of the 7th European Conference on Soil Mechanics and Foundation Engineering, Brighton, 3(13), 239-247.

Park K-H. 2004. Elastic Solution for Tunneling-Induced Ground Movements in Clays, Int. J. Geomech, 4, 310-318.

Park, K-H. 2005. Analytical solution for tunnelling-induced ground movement in clays. Tunnelling and Underground Space Technology, 20 : 249-261.

Peck, P.B. 1969. Deep excavations and tunneling in soft ground .Proceedings of the 7th International Conference on Soil Mechanics and Foundation Engineering. Mexico City: Sociedad Mexicana de Mecanica de Suelos A C, 225-290.

Pourtaghi, A., and Lotfollahi-Yaghin, M.A. 2012. Wavenet ability assessment in comparison to ANN for predicting the maximum surface settlement caused by tunneling, Tunnelling and Underground Space Technology,28:257-271.

Rowe, R.K, Lo, K.Y. and Kack, G.J. 1983. A method of estimating SS above tunnels constructed in soft ground .Canadian Geotechnical Journal. 20(8), 11-22.

Shen S.L., and $\mathrm{Xu}$, Y.S. 2011. Numerical evaluation of land subsidence induced by groundwater pumping in Shanghai. Canadian Geotechnical Journal, 48(9): 1378-1392.

Shen, S-L., Ma, L., Xu, Y-S., and Yin, Z-Y. 2013. Interpretation of increased deformation rate in aquifer IV due to groundwater pumping in Shanghai. Canadian Geotechnical Journal, 50(11), 1129-1142. 
Shen, S-L., Wu, H-N., Cui, Y-J., and Zhen, Y-Y. 2014. Long term settlement behaviour of metro tunnels in the soft deposits of Shanghai. Tunneling and Underground Space Technology, 40, 309-323.

Shen, S-L.; Cui, Q-L.; Ho, C.E.; and Xu, Y.S. 2016. Ground Response to Multiple Parallel Microtunneling Operations in Cemented Silty Clay and Sand. Journal of Geotechnical and Geoenvironmental Engineering, 142(5), 04016001(1-11).

Suwansawat, S., and Einstein, H.H. 2007. Describing settlement troughs over twin tunnels using a superposition technique. Journal of Geotechnical and Geoenvironmental Engineering, 133(4), 445-468.

Verruijt, B. 1996. SSs due to deformation of a tunnel in an elastic half plane, Geotechnique. $46(4), 753-756$.

Vu, M.N., Broere, W., and Bosch, J. 2016. Volume Loss in shallow tunnelling.Tunnelling and Underground Space Technology 59, 77-90.

Wu, H.N., Shen, S.L., Chai, J.C., Zhang, D.M., and Xu, Y.S. 2015b. Evaluation of the train-load-induced settlement of metro tunnels in Shanghai,Geotechnical Engineering, ICE Proceedings, 168(5), 396-409.

Wu, H.N., Shen, S.L., Liao, S.M., and Yin, Z.Y. 2015a. Longitudinal structural modelling of shield tunnels considering shearing dislocation between segmental rings, Tunneling and Underground Space Technology,50, 317-323.

Zhang, D., Li, P., Hou, Y., and Luo, J. 2009. Experimental study on safety control of buildings during construction of shallow-buried soft rock tunnel with large section, Yan shi li xue Yu Gong cheng Xue bao. Chinese J. Rock Mech. Eng. 28 (1), 95-102. (in Chinese)

Zhang, Y. 2011. Study on the laws of surface subsidence induced by shield construction and control technology of Xi'an Metro, Doctor Degree of Engineering, Xi'an University of science and technology. (in Chinese) 


\section{List of symbols :}

$w$

natural water content $(\%)$

$G_{\mathrm{s}} \quad$ grain density $\left(\mathrm{g} / \mathrm{cm}^{3}\right)$

$\gamma \quad$ natural unit weight $\left(\mathrm{kN} / \mathrm{m}^{3}\right)$

$\gamma_{\mathrm{d}} \quad$ dry unit weight $\left(\mathrm{kN} / \mathrm{m}^{3}\right)$

$S_{\mathrm{r}} \quad$ degree of saturation (\%)

$e_{0} \quad$ void ratio

$w_{\mathrm{L}} \quad$ liquid limit $(\%)$

$w_{\mathrm{p}} \quad$ plastic limit $(\%) \mathrm{S}_{\mathrm{t}}$-sensitivity

$I_{\mathrm{p}} \quad$ plasticity index

$I_{\mathrm{L}} \quad$ liquidity index

$c^{\prime} \quad$ effective cohesion $(\mathrm{kPa})$

$\varphi^{\prime} \quad$ effective frictional angle $\left(^{\circ}\right)$

$c_{\mathrm{u}} \quad$ undrained cohesion $(\mathrm{kPa})$

$\varphi_{\mathrm{u}} \quad$ undrained frictional angle $\left(^{\circ}\right)$

$\psi \quad$ dilatancy angle $\left(^{\circ}\right)$

$K_{0} \quad$ coefficient of lateral earth pressure at rest

$K_{20} \quad$ coefficient of vertical permeability $(\mathrm{cm} / \mathrm{s})$

$C_{\mathrm{v}} \quad$ coefficient of consolidation $\left(10^{-3} \mathrm{~cm}^{2} / \mathrm{s}\right)$

$E_{\mathrm{s}} \quad$ compression modulus (MPa)

$E_{0} \quad$ deformation modulus (MPa)

$v_{\mathrm{u}} \quad$ undrained Possion's ratio, which is equal 0.5

$v_{0} \quad$ effective Possion's ratio, which is equal $v$

$E_{\mathrm{u}} \quad$ undrained elastic modulus (MPa)

$a_{\mathrm{v}} \quad$ coefficient of compressibility $\left(\mathrm{MPa}^{-1}\right)$ 


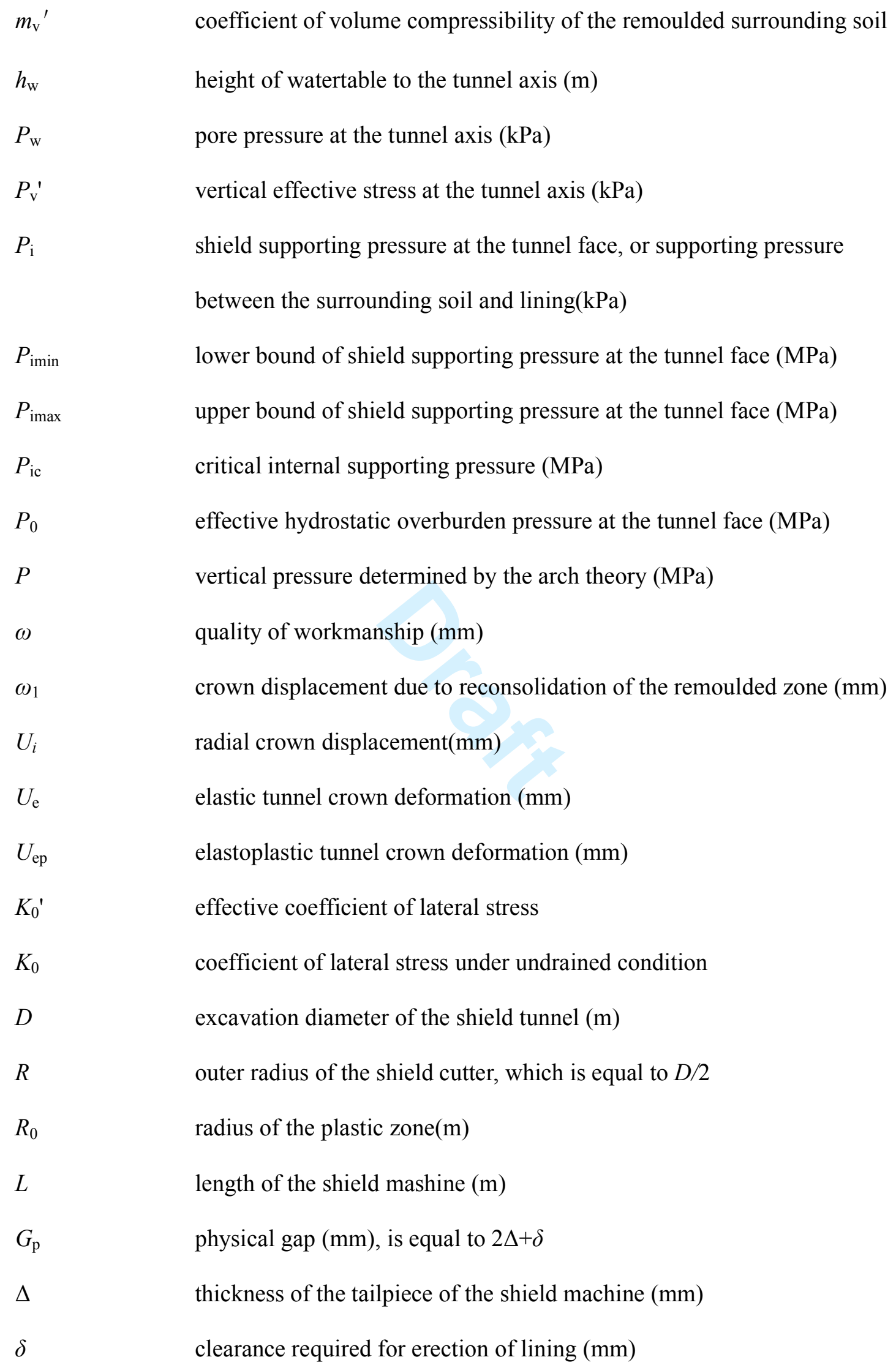




\begin{tabular}{|c|c|}
\hline$\delta_{0}$ & the yawing value of shield head (mm) \\
\hline$U_{3 D}^{*}$ & equivalent three dimensional elastoplastic deformation $(\mathrm{mm})$ \\
\hline$\Omega$ & dimensionless axial displacement ahead of the tunnel face \\
\hline$N$ & stability number, which is equal to $\left(\gamma H-P_{\mathrm{i}}\right) / c_{\mathrm{u}}$ \\
\hline$H$ & buried depth of the tunnel axis (m) \\
\hline$H_{0}$ & overburden depth of the surrounding soil $(\mathrm{m})$, is equal to $H-R$ \\
\hline$S_{\mathrm{x}}$ & surface settlement at any monitoring point (mm) \\
\hline$S_{\max }$ & maximum surface settlement $(\mathrm{mm})$ \\
\hline$x$ & horizontal displacement from the tunnel center (m) \\
\hline$V_{1}$ & coefficient of ground volume loss $(\%)$ \\
\hline$i$ & settlement trough width $(\mathrm{m})$ \\
\hline$g_{\mathrm{i}}$ & component of GP (mm) \\
\hline$g_{t}$ & total value of components of GP (mm) \\
\hline$g_{t l}$ & lower bound of the total GP $(\mathrm{mm})$ \\
\hline$g_{t u}$ & upper bound of the total GP (mm) \\
\hline$g_{\text {tav }}$ & average value of the $g_{\mathrm{tl}}$ and $g_{\mathrm{tu}}(\mathrm{mm})$ \\
\hline$k$ & ratio of the STW to the buried depth \\
\hline $\bar{k}$ & average value of the STW \\
\hline$u_{\mathrm{c}}$ & vertical deformation at the tunnel crown (mm) \\
\hline$P_{\text {it }}$ & total support force at the tunnel face $(\mathrm{kN})$ \\
\hline$P_{\mathrm{v}}$ & vertical force at the tunnel crown $(\mathrm{kN})$ \\
\hline$P_{\mathrm{h}}$ & horizontal force at the tunnel wall $(\mathrm{kN})$ \\
\hline$\varpi$ & effective fill rate of grouting into the shield tail $\left({ }^{\circ}\right)$ \\
\hline$\theta_{0}$ & angle concerned with the main body yawing of the shield machine $\left(^{\circ}\right)$ \\
\hline$\kappa$ & shield yawing ratio \\
\hline
\end{tabular}


$\alpha$

$m$

$\Delta \sigma^{\prime}$

$\sigma_{1}$

$\sigma_{2}$

shield yawing angle $\left(^{\circ}\right)$

the bead number spans the upper semicircle of the shield hood

average variation of effective stress in the plastic region (MPa)

average initial stress in the plastic region $(\mathrm{MPa})$

average residual stress in the plastic region $(\mathrm{MPa})$ 


\section{Figure captions list}

Figure 1. Some features of SS trough

Figure 2. Definition of gap parameter (after Lee and Rowe 1992)

Figure 3. Location of the Bell Tower station and the South Gate station in Xi'an Metro line 2

Figure 4. Profile of soil layers, tunnel and adjacent structures from the Bell Tower station to the South Gate station (Units:m; Vertical scale: 1:200; horizontal scale: 1:1000)

Figure 5. Particle size distributions of the different soil types

Figure 6. Monitoring system and installation method for the transverse SS: (a) Monitoring system of the transverse SS; (b) Installation of the single monitoring point.

Figure 7. Measured SS troughs between the Bell Tower station and the South gate station

Figure 8. Surface settlement characteristics: (a) $i$ versus $H$; (b) $S_{\max } / g$ versus $H / D$; (c) $S_{\max }$ versus $g$

Figure 9. Relationship between surface movement behavior and earth pressure balance of the shield

Figure 10. Surface movement types versus internal supporting pressure

Figure 11. Gap due to shield yawing

Figure 12. Comparison of estimations and measured results of SS for several sections:

(a)13+290; (b) 13+341; (c)13+353; (d)13+371; (e)13+389; (f)13+401; (g)13+460;

(h)13+680; (i)13+734; (j)13+782; (k)13+849; (1)14+211; (m)14+230; (n)14+290. 


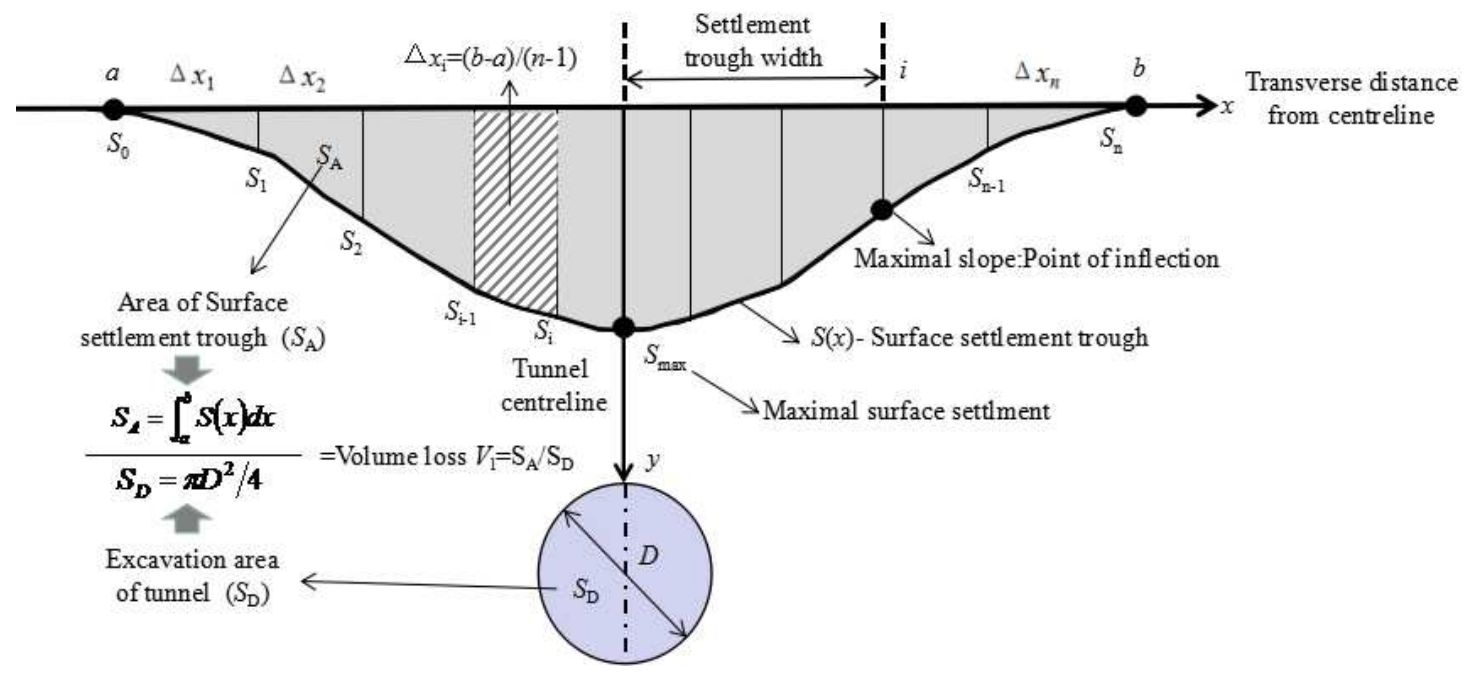

Figure 1. Some features of SS trough 


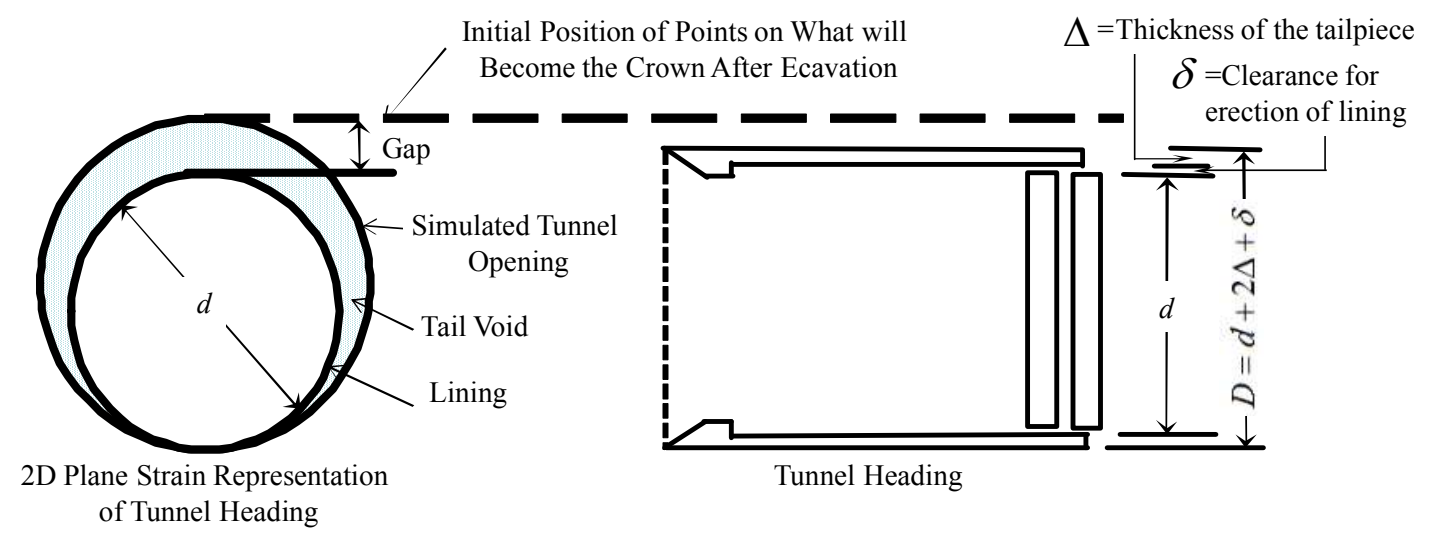

Figure 2. Definition of gap parameter (after Lee and Rowe 1992) 


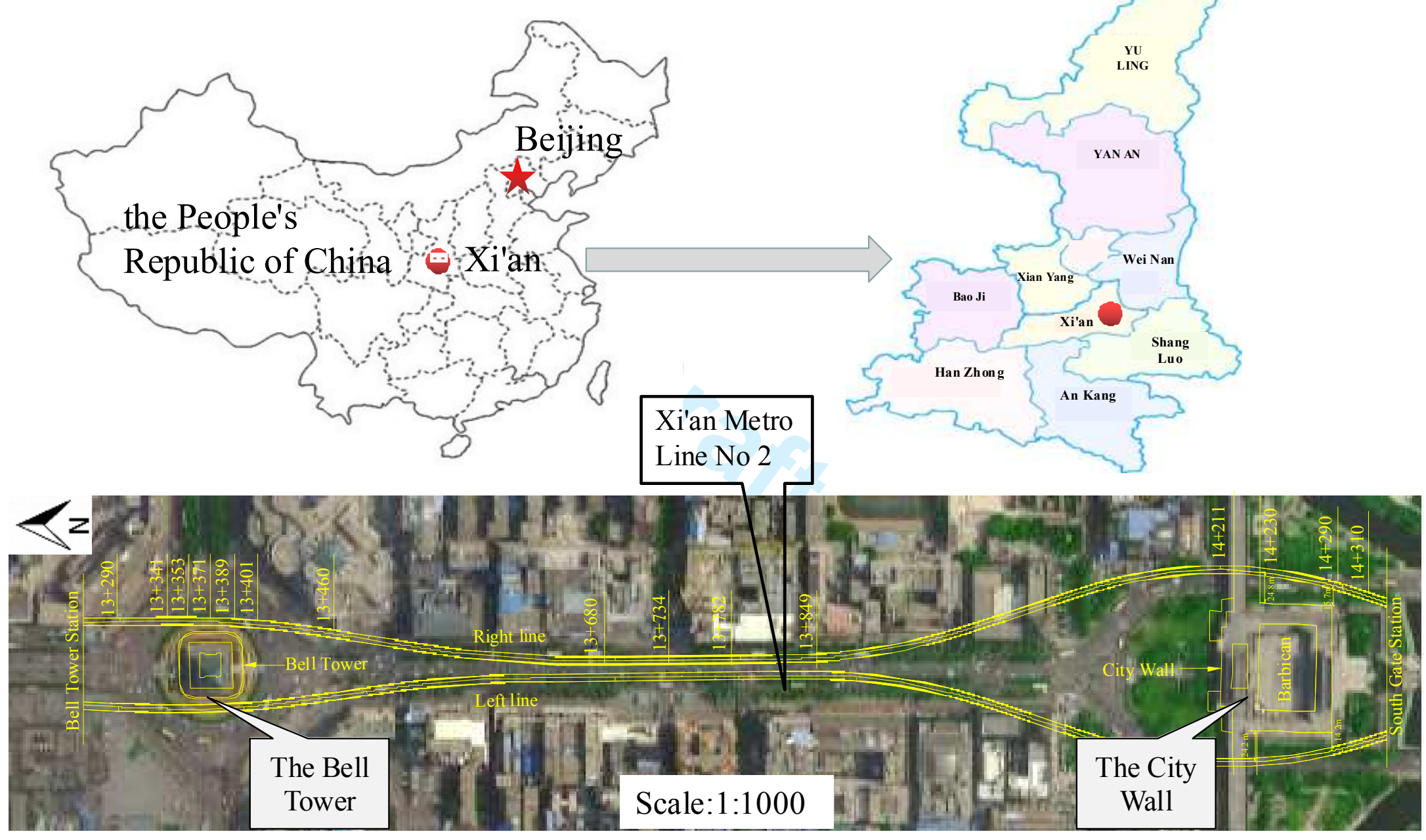

Figure 3. Location of the Bell Tower station and the South Gate station in Xi'an Metro line 2. 


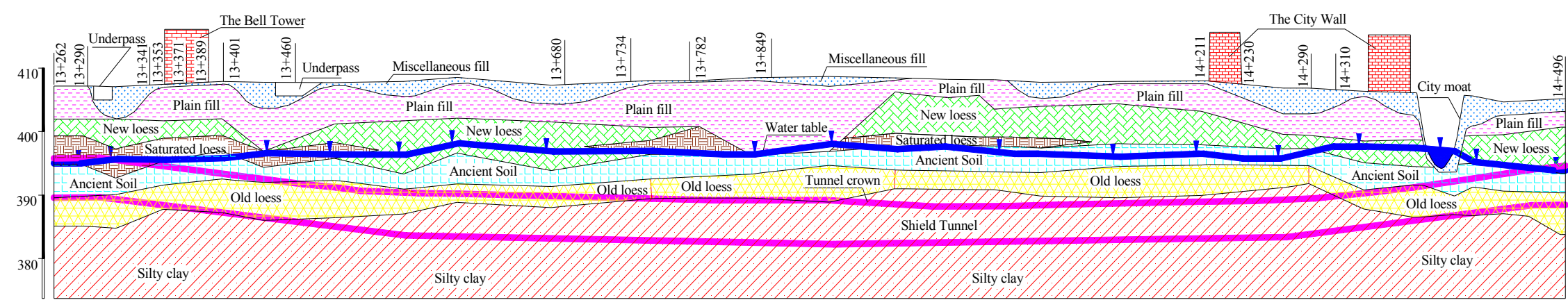

Figure 4. Profile of soil layers, tunnel and adjacent structures from the Bell Tower station to the South Gate station (Units:m; Vertical scale: 1:200; horizontal scale: 1:1000) 


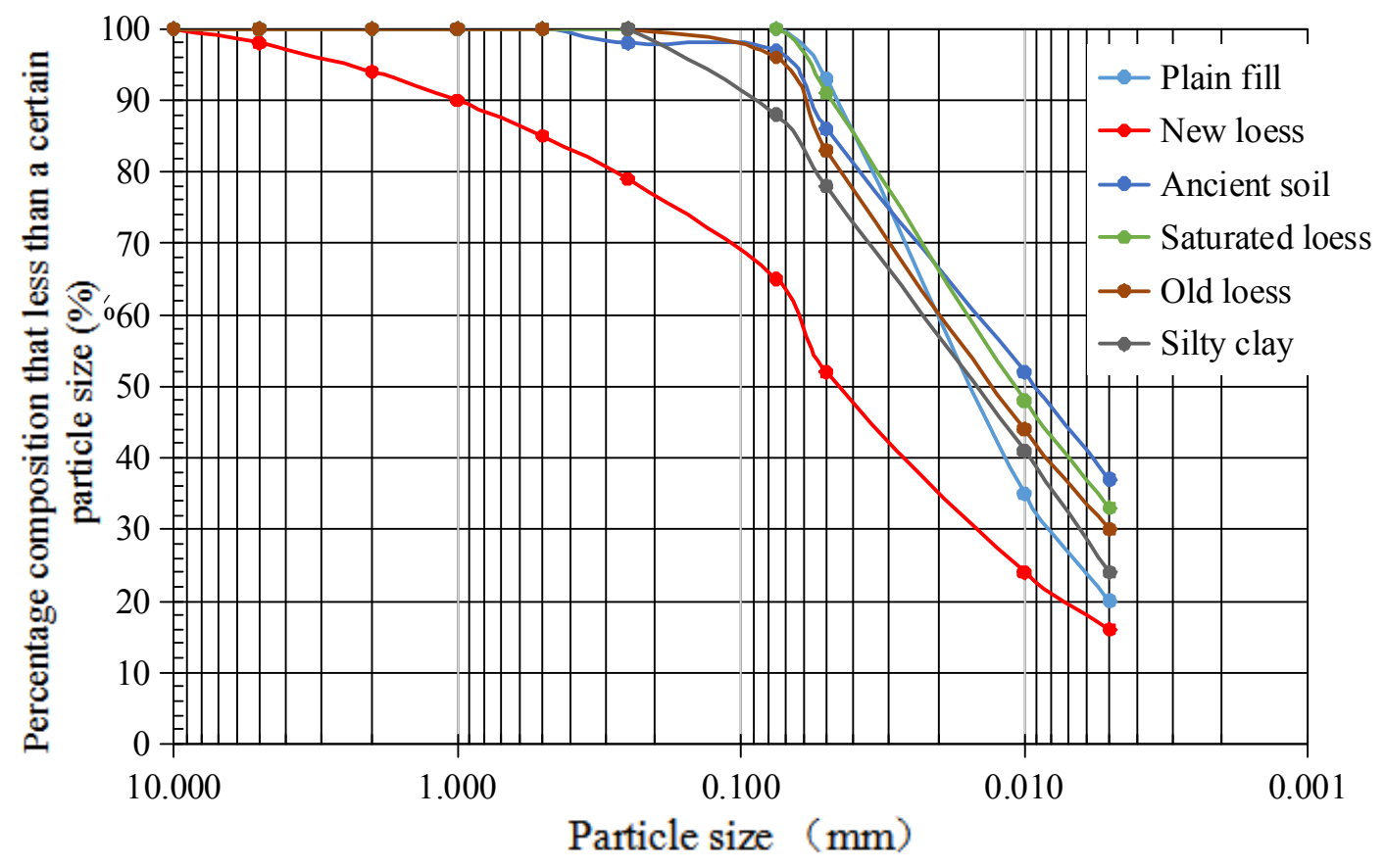

Figure 5. Particle size distributions of the different soil types 


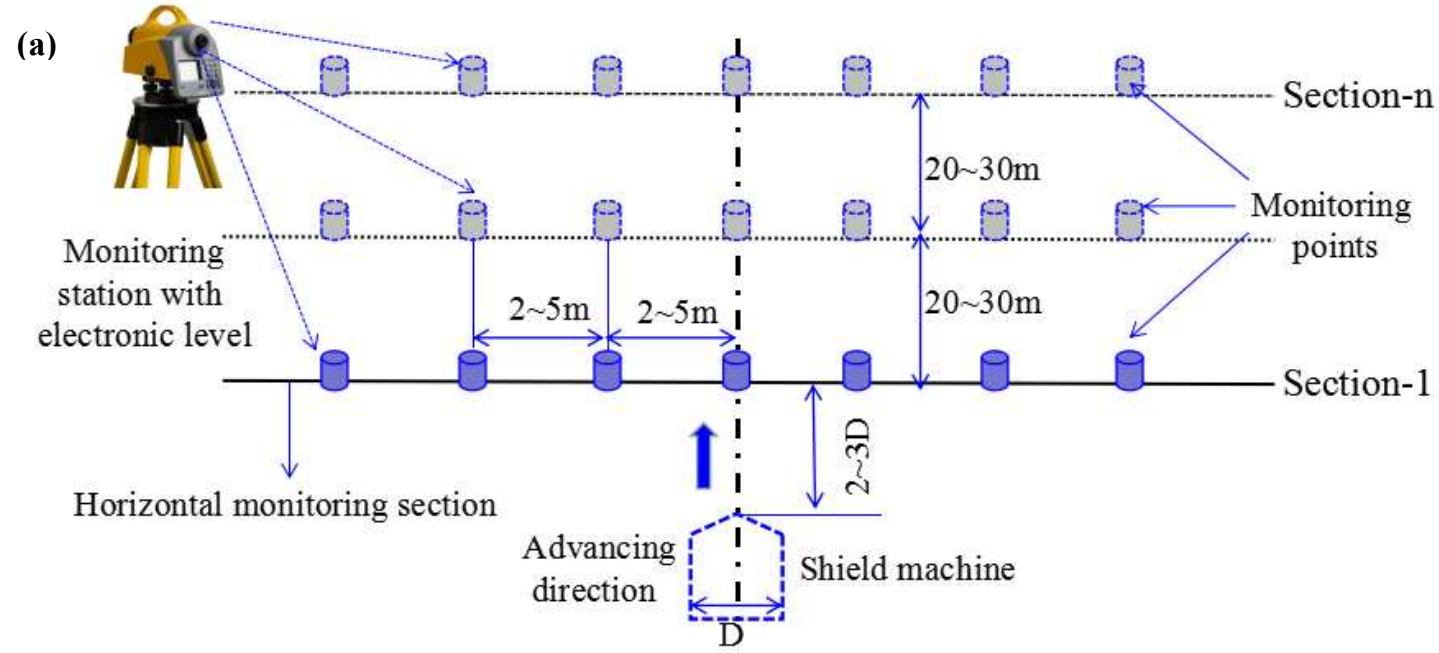

(b) Metal box Steel ball

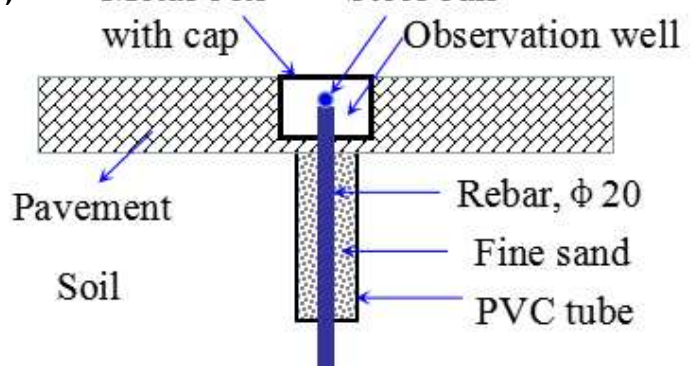

Figure 6 Monitoring system and installation method for the transverse SS: (a)

Monitoring system of the transverse SS; (b) Installation of the single monitoring point. 


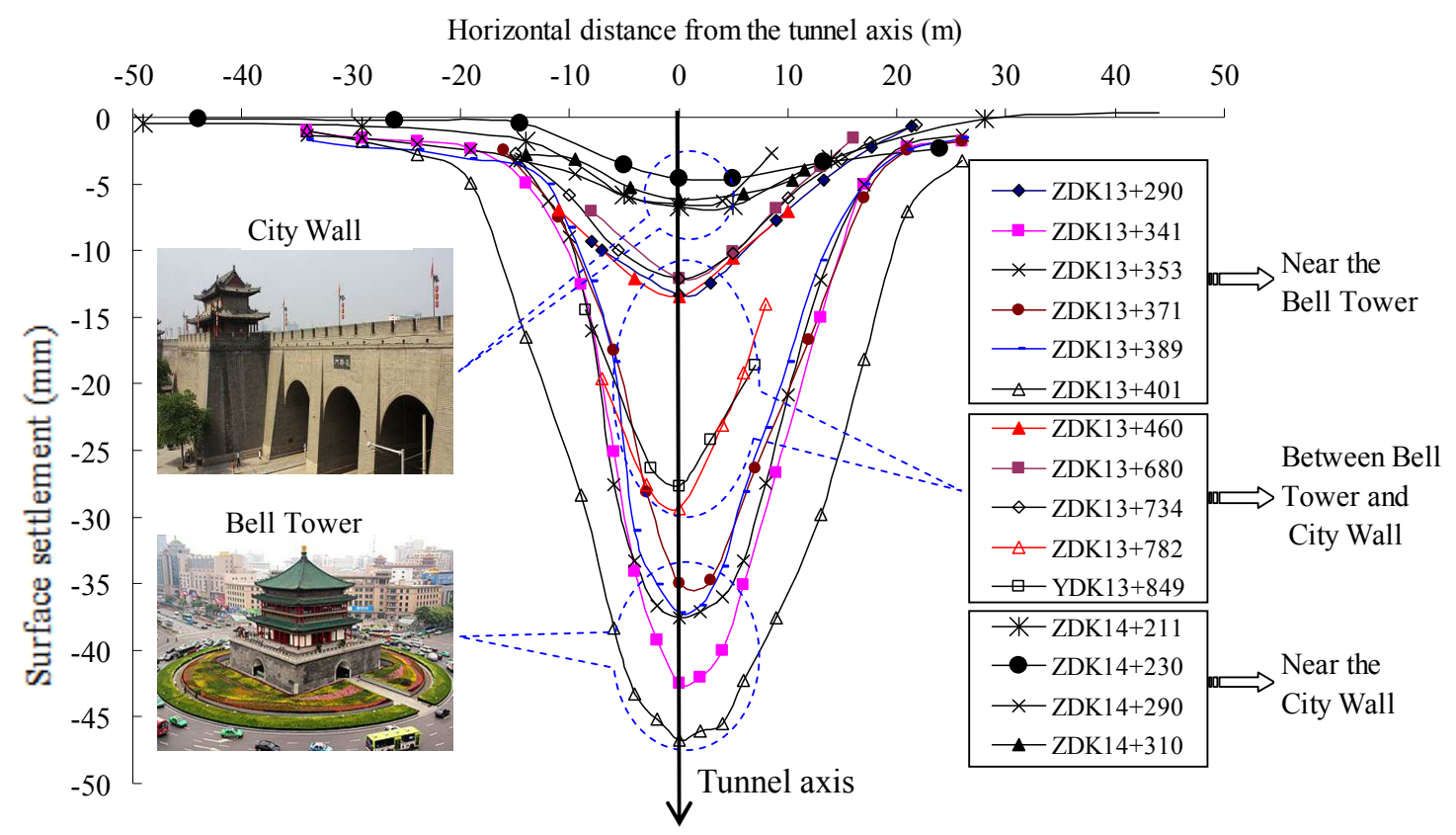

Figure 7. Measured SS troughs between the Bell Tower station and the South gate station 

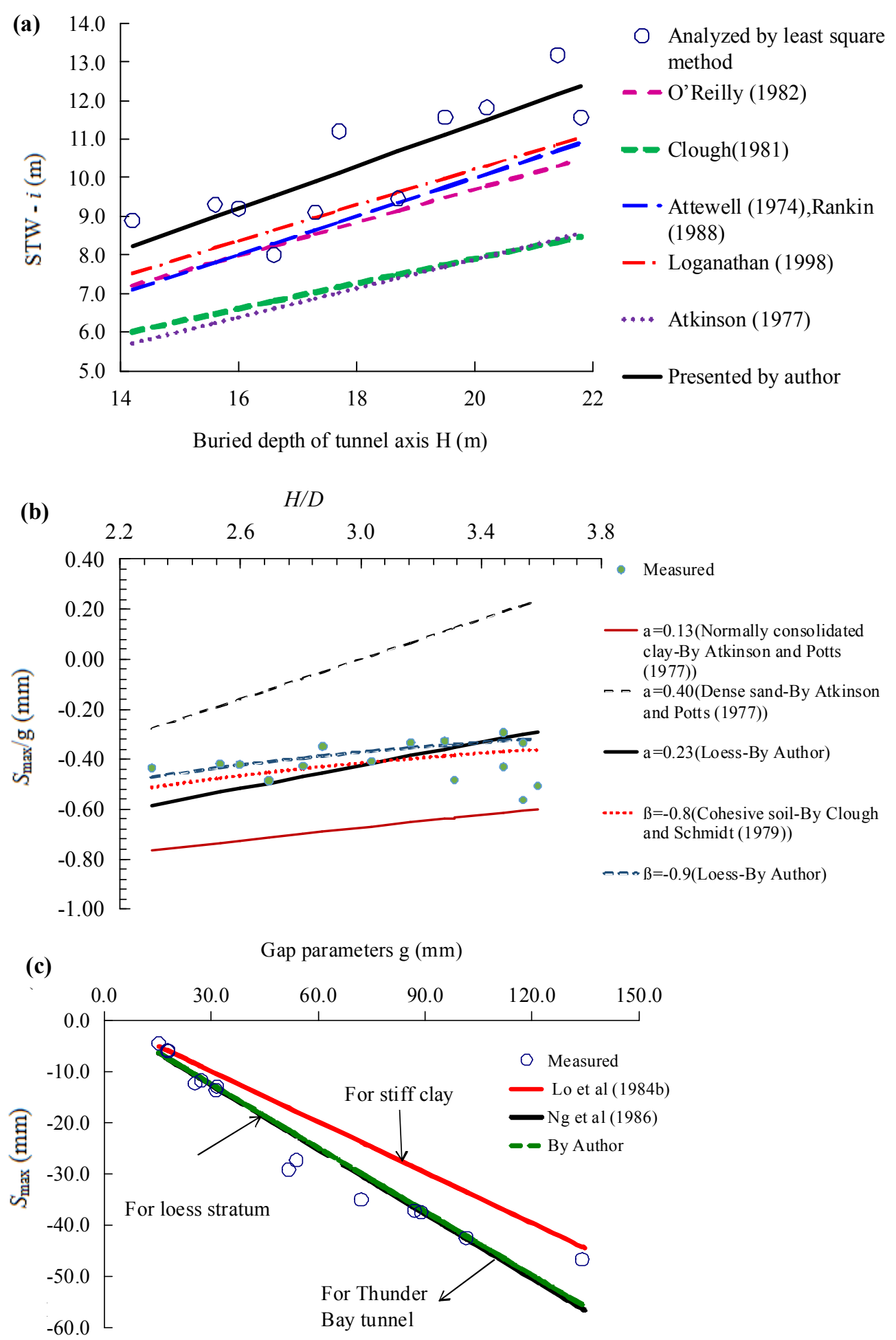

Figure 8. Surface settlement characteristics: (a) $i$ versus $H$; (b) $S_{\max } / g$ versus $H / D$; (c) $S_{\max }$

\section{versus $g$}



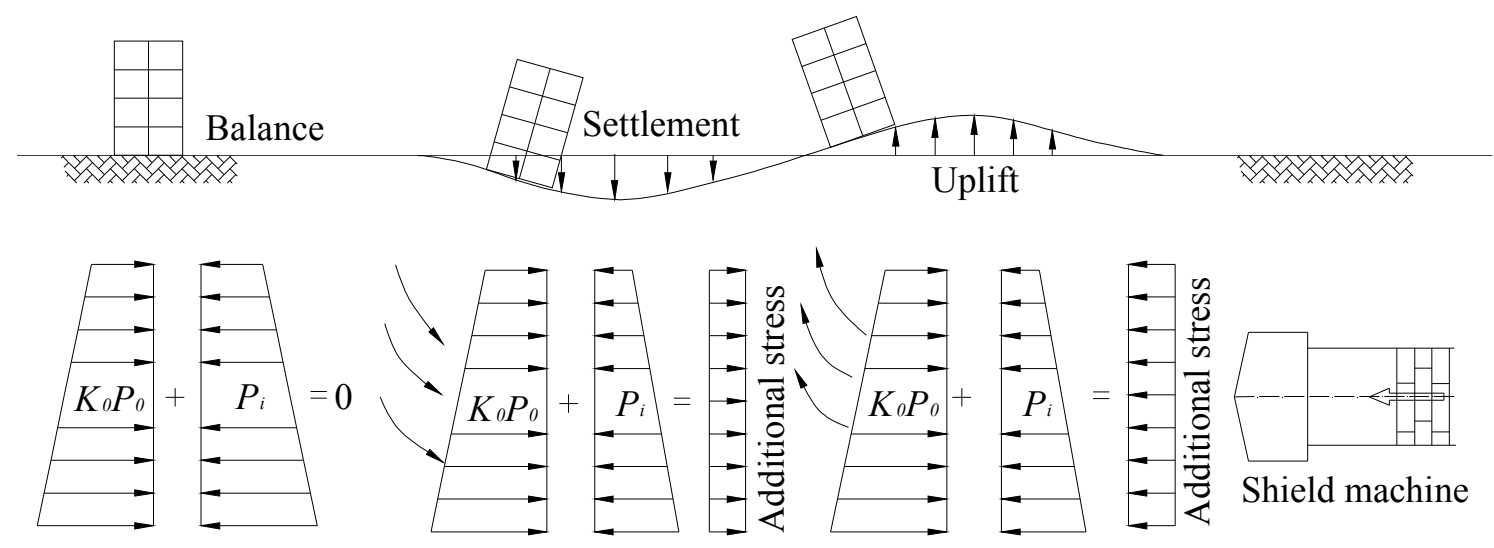

Figure 9. Relationship between surface movement behavior and earth pressure balance of the shield 

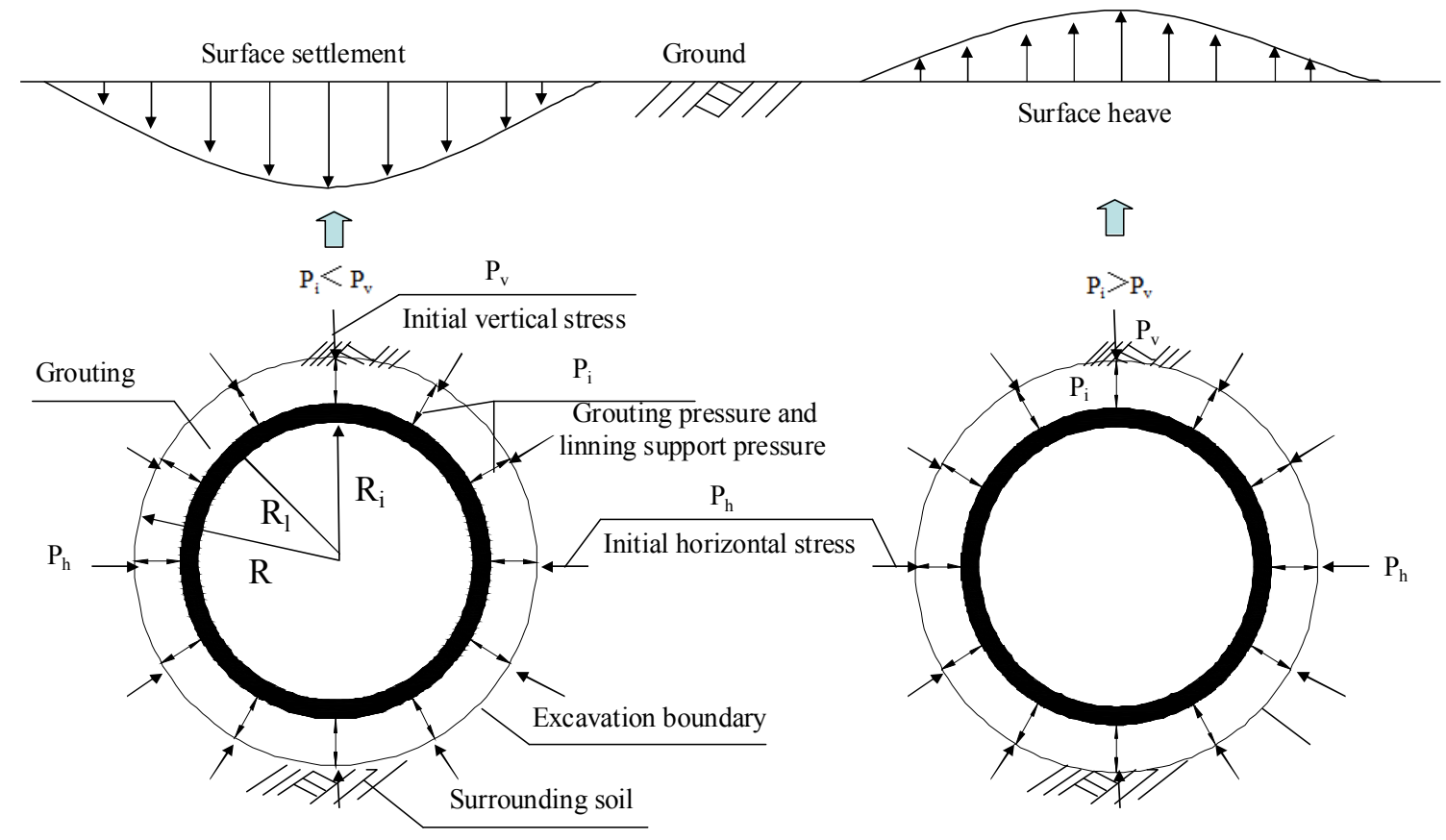

Figure 10. Surface movement types versus internal supporting pressure 


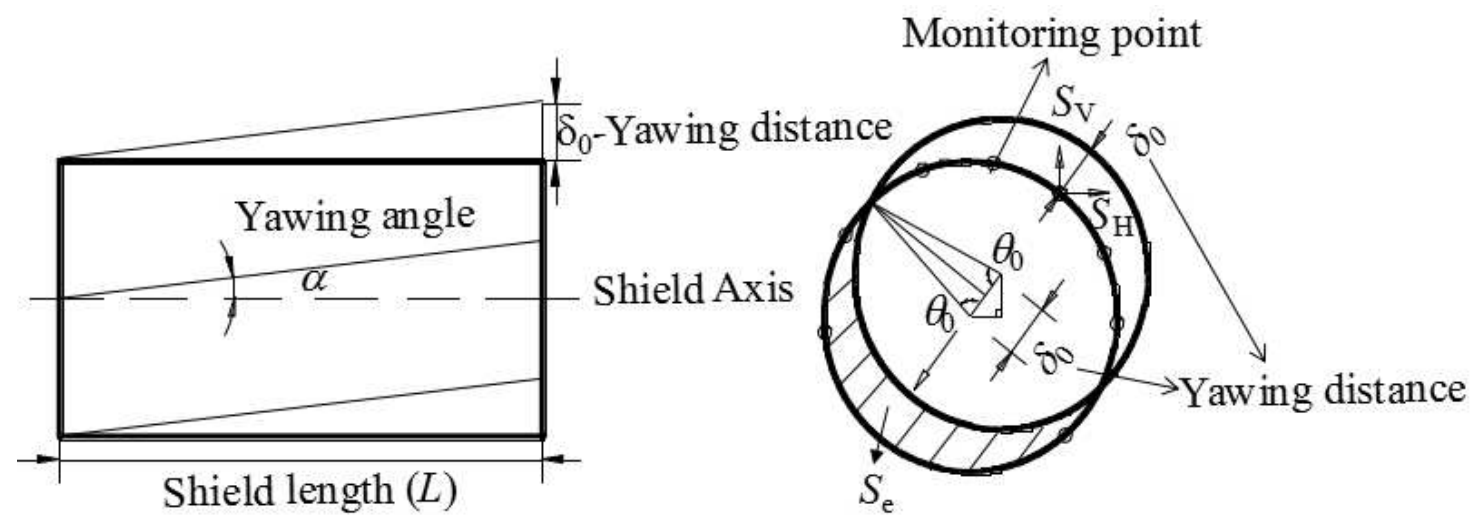

Figure 11. Gap due to shield yawing 
(a) Horizontal distance from the tunnel center (m)

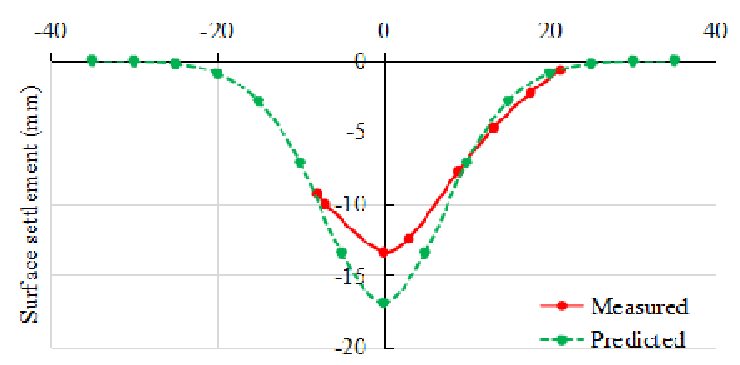

(c)

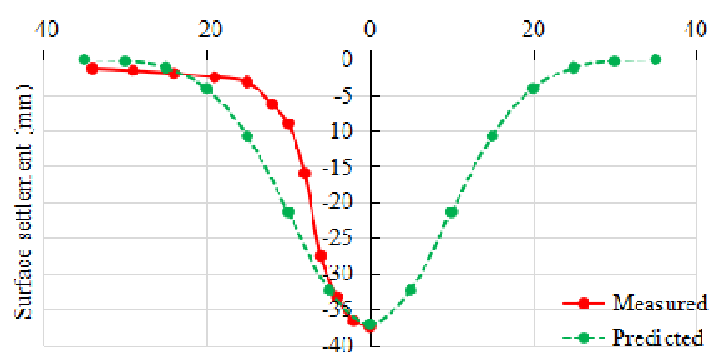

(e) Horizontal distance from the tunncl center (m)

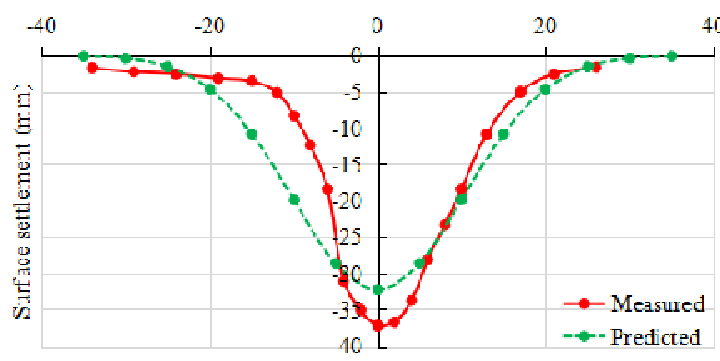

(g)

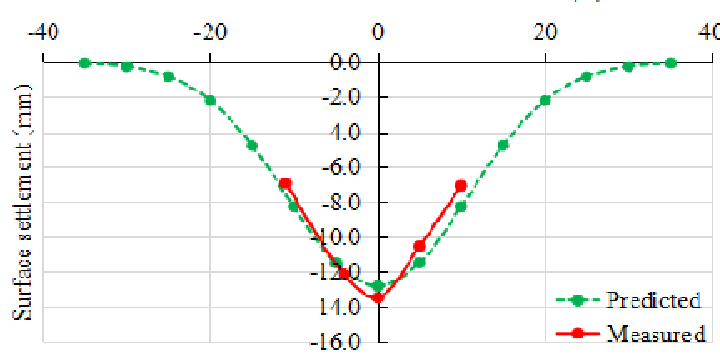

(i)

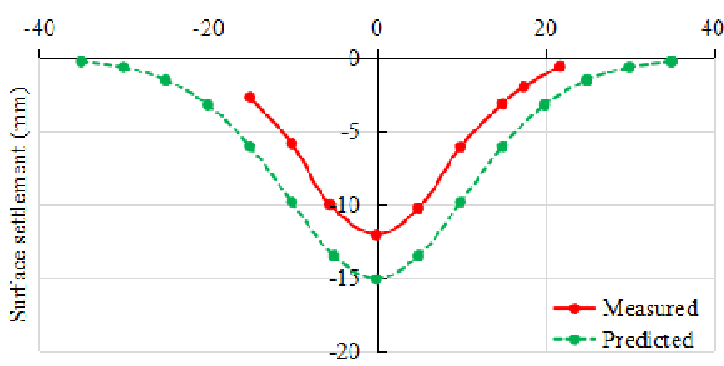

(b) Horizontal distance from the tumnel center (m)

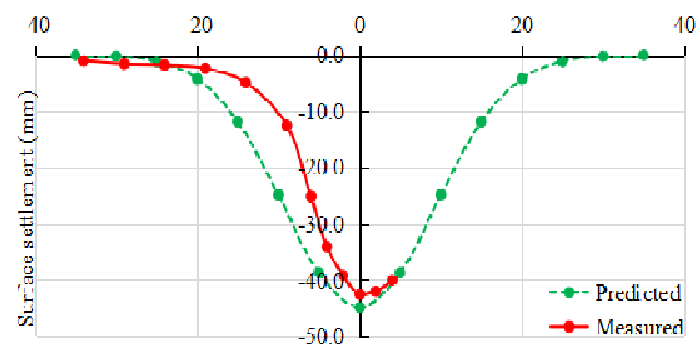

(d) Horizontal distance from the tunncl ccntcr (m)

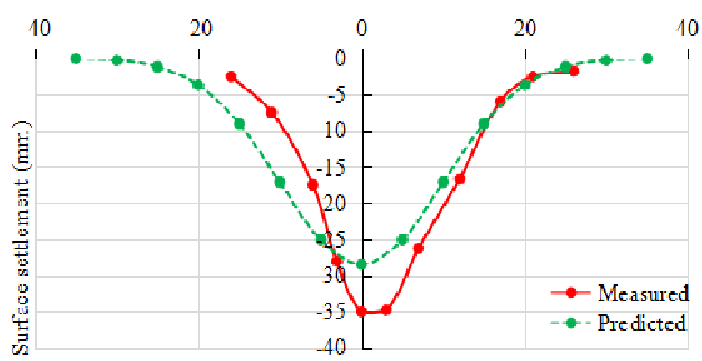

(f) Horizcntal distance from the turnel center (m)

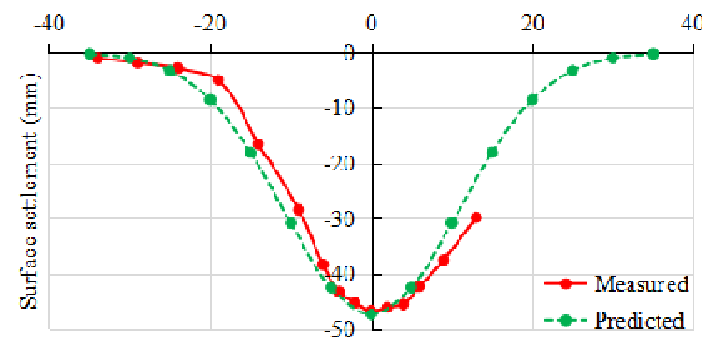

(h) Horizontal distance from the tunnel center (m)

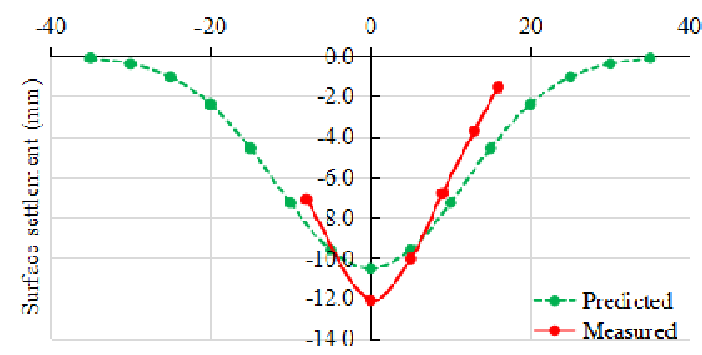

(j) Horizunial distance from the turnel center (III)

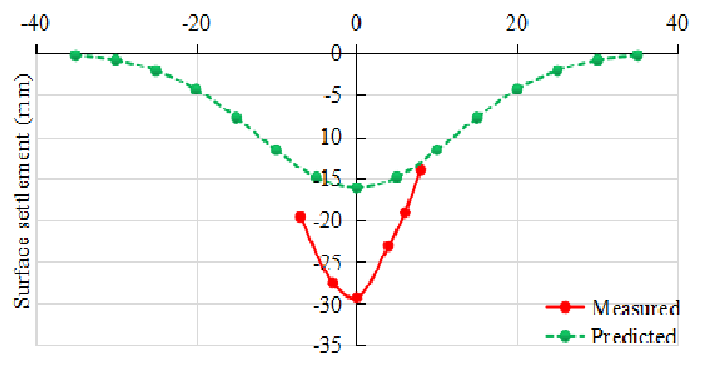



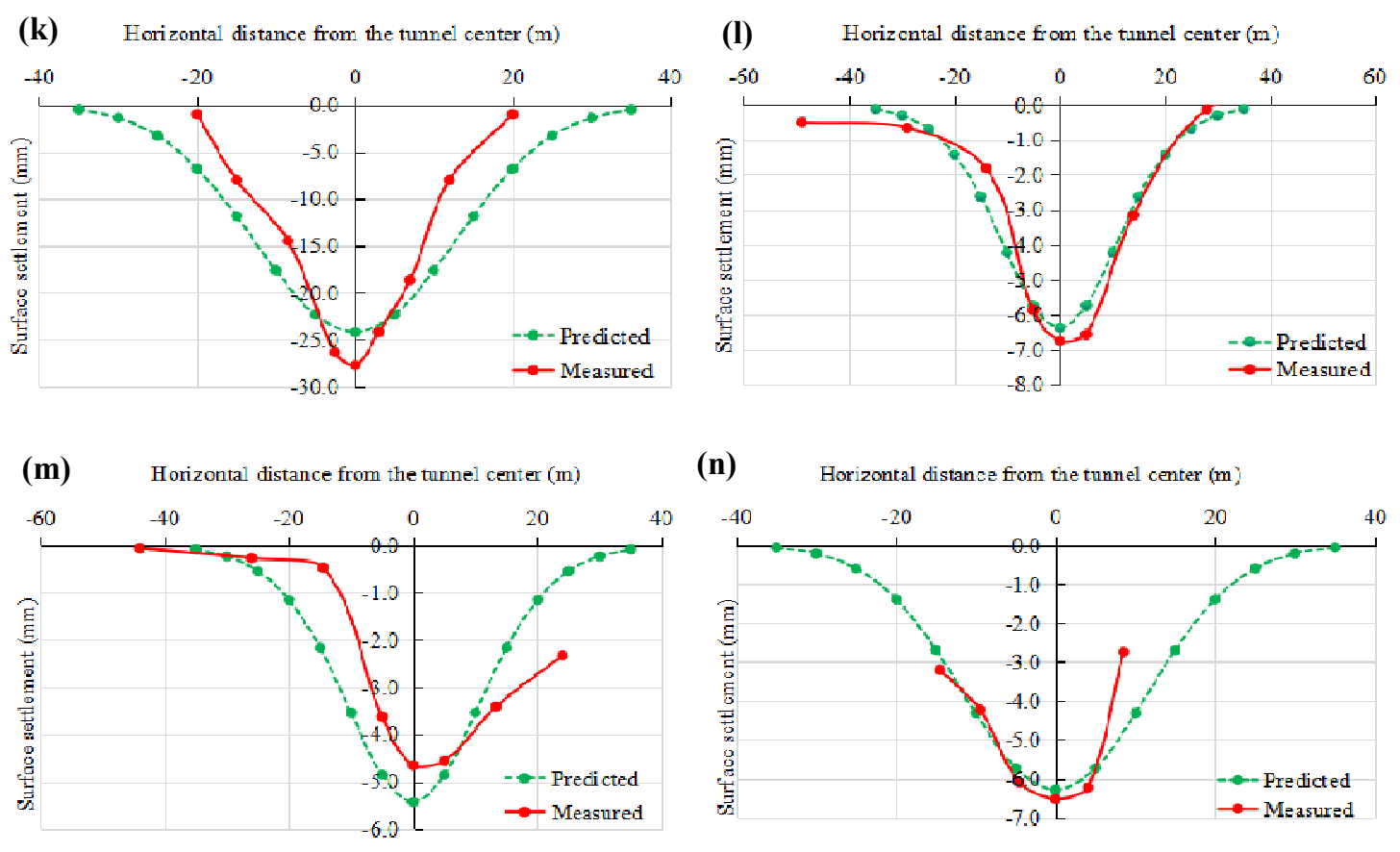

(n) Horizontal distance from the tunnel center (m)

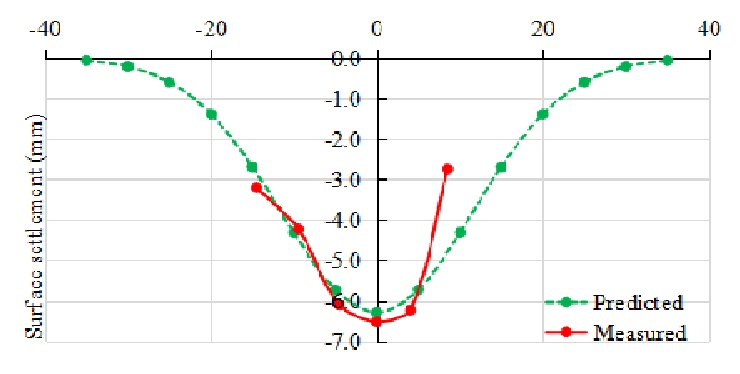

Figure 12. Comparison of estimations and measured results of SS for several sections:

(a)13+290; (b) 13+341; (c)13+353; (d)13+371; (e)13+389; (f)13+401; (g)13+460;

(h)13+680; (i)13+734; (j)13+782; (k)13+849; (l)14+211; (m)14+230; (n)14+290. 


\section{Table Captions:}

Table 1 Prediction equations and application conditions for settlement trough width (Based on Han 2006, summarized by the authors)

Table 2 Estimation methods of maximal surface settlement

Table 3 Some empirical values for volume loss

Table 4 Physical and mechanics parameters of soils by laboratory tests near the Bell Tower station $(13+290-13+734)$ and the South Gate station $(13+782-14+310)$.

Table 5 The empirical equation of $K_{0}(\mathrm{Hu} 1997)$

Table 6 Weighted average of physical and mechanics parameters of soils above the tunnel

Table 7 Surface settlement behaviors of Xi'an Metro

Table 8 Gap due to shield intermittent alignment in different monitoring sections

Table 9 Components of the total gap parameter in different monitoring sections 
Table 1. Prediction equations and application conditions for settlement trough width (Based on Han 2006, summarized by the authors)

\begin{tabular}{lll}
\hline References & Coefficient of settlement trough width $(k)$ & Application conditions \\
\hline Knothe (1957) & $1 / \sqrt{2 \pi} \tan \left(45^{\circ}-\varphi / 2\right)$ & Rock mass \\
& & \\
Han et al (2006) & $1-0.02 \varphi$ & $\begin{array}{l}\text { Cohesiveless Soil, soft soil, stiff clay in London }(\varphi \text { is } \\
\left.\text { is the internal friction angle }\left({ }^{\circ}\right)\right)\end{array}$ \\
Peck(1969) & $0.5(H / \mathrm{D})^{1-n}(n=0.8 \sim 1.0)$ & All kinds of soil (measured data) \\
Attewell \& Farmer(1974), Rankin (1988) & 0.5 & Clayed soil in UK (measured data and centrifuge tests) \\
Clough and Schmidt(1981) & $0.5(H / \mathrm{D})^{-0.2}$ & Clayed soil in UK (measured data) \\
Loganathan and Poulos (1998) & $0.575(H / \mathrm{D})^{-0.1}$ & Clayed soil \\
Atkinson and Potts(1977) & $0.25+0.125(D / H)$ & Loose sand (measured data) \\
& $0.375+0.0625(D / H)$ & Dense and over-consolidated clay (model tests) \\
O'Reilly and New (1982) & $0.43+1.1 / H$ & Clayed soil in UK $(3 \leqslant H \leqslant 34 \mathrm{~m})$ \\
Wang et al (2014) & $0.28-0.1 / H$ & Granular soil in UK $(6 \leqslant H \leqslant 10 \mathrm{~m})$ \\
\hline
\end{tabular}


Table 2 Estimation methods of maximal surface settlement

\begin{tabular}{lll}
\hline Reference & Equation & Terms explanation \\
\hline Oteo and Moya(1979) & $-\psi \gamma D^{2}(0.85-v) / E$ & $\begin{array}{l}\Psi \text { is the empirical parameter and equal to } 0.3 \sim 0.4 ; E \text { is the tensile } \\
\text { modulus of elasticity. }\end{array}$ \\
Verruijt \& Booker(1996) & $-R^{2}\left(V_{1}+2 \delta\right) / H$ & Used under undrained condition, when $\alpha=1.0$ in above equation. \\
Loganathan \& Poulos (1998) & $-4 V_{\mathrm{l}}(1-v) R^{2} / H$ & $v$ is the Poisson's ratio. \\
Gonzales \& Sagaseta (2001) & $-R\left(V_{1}+2 \delta\right)(R / H)^{(2 \alpha-1)}$ & $\begin{array}{l}\alpha \text { is the coefficient of volume compressibility, } \alpha \leq 2.0 ; \alpha=1.0, \text { when } H / D \\
>4.0 \text { and in clayey soil; } \alpha>1.0, \text { in granular soil. } \delta \text { is the ovalization; } \rho\end{array}$ \\
& $-g r_{0} / H+0.75 \gamma r_{0}^{2} \ln H / E_{\mathrm{u}}$ & $\begin{array}{l}\text { is the relative ovalization and equal to } \delta / \varepsilon, \varepsilon=V_{1} / 2 . \\
r_{0} \text { is the inner radius of lining, used in the shallow round tunnel and }\end{array}$ \\
undrained condition, $g$ is the gap parameter.
\end{tabular}


Table 3. Some empirical values for volume loss

\begin{tabular}{lclc}
\hline \multicolumn{1}{c}{ Soil type (Han, 2006) $D=3.0 \sim 13.0 \mathrm{~m}$} & Volume loss $V_{1}(\%)$ & Soil type (O'Reilly and New 1982) $D=3.0 \sim 3.5 \mathrm{~m}$ & Volume loss $V_{1}(\%)$ \\
\hline Silty clay, sandy silt (NATM) & $0.47-2.56$ & Clayey soil & $0.5 \sim 2.5$ \\
Completely-weathered limestone (NATM) & $0.90-1.60$ & Stiff clay with fractures & $1.0 \sim 2.0$ \\
Saturated silty clay (EPB) & $0.35-6.90$ & Moraine soils (no air support pressure) & $2.0 \sim 2.5$ \\
Hard-plastic clay (NATM) & $0.40-0.45$ & Moraine soils (air support pressure $)$ & $1.0 \sim 1.5$ \\
Loess (NATM, EPB) & $0.22-0.75$ & New deposit silty clay $\left(c_{\mathrm{u}}=10 \sim 40 \mathrm{kPa}\right)$ & $2.0 \sim 10.0$ \\
Gravel sand, gravel (NATM, EPB) & $0.55-1.71$ & Unsaturated cohesionless soil & $2.0 \sim 5.0$ \\
Artificial fill or Sandy soil (EPB) & $1.43-3.01$ & Saturated cohesionless soil & $2.0 \sim 10.0$ \\
Stiff clay & $1.00-2.00$ & Artificial fill & $>10.0$
\end{tabular}


Table 4. Physical and mechanics parameters of soils by laboratory tests near the Bell Tower station $(13+290-13+734)$ and the South

\section{Gate station $(13+782-14+310)$}

\begin{tabular}{|c|c|c|c|c|c|c|c|c|c|c|c|c|c|c|c|c|c|c|c|}
\hline \multicolumn{20}{|c|}{$13+290$ and $13+734$ (Near the Bell Tower) } \\
\hline Soil types & $w$ & $G_{\mathrm{s}}$ & $\gamma$ & $\gamma_{\mathrm{d}}$ & $S_{\mathrm{r}}$ & $e_{0}$ & $w_{\mathrm{L}}$ & $w_{\mathrm{p}}$ & $I_{\mathrm{p}}$ & $I_{\mathrm{L}}$ & $c^{\prime}$ & $\varphi^{\prime}$ & $c_{\mathrm{u}}$ & $K_{0}$ & $K_{20} \times 10^{-5}$ & $C_{\mathrm{v}}$ & $a_{\mathrm{v} 1-2}$ & $E_{\mathrm{s}}$ & $S_{\mathrm{t}}$ \\
\hline Plain fill & 25.8 & 2.72 & 17.5 & 13.9 & 74 & 0.955 & 32.9 & 19.8 & 13.1 & 0.46 & - & - & 15 & 0.700 & - & - & 0.37 & 5.3 & - \\
\hline $\begin{array}{c}\text { Saturated } \\
\text { loess }\end{array}$ & 25.5 & 2.72 & 19.7 & 15.7 & 94 & 0.783 & 32.3 & 19.5 & 12.8 & 0.47 & 35 & 22.2 & 26 & - & - & - & 0.29 & 6.0 & \\
\hline Silty clay & 22.0 & 2.72 & 20.2 & 16.6 & 93 & 0.640 & 32.2 & 19.5 & 12.7 & 0.20 & 50 & 27.3 & 35 & 0.609 & 0.0144 & 1.06 & 0.21 & 7.8 & 1.7 \\
\hline \multicolumn{20}{|c|}{$13+782$ and $14+310$ (Near the South Gate) } \\
\hline Soil types & $w$ & $G_{\mathrm{s}}$ & $\gamma$ & $\gamma_{\mathrm{d}}$ & $S_{\mathrm{r}}$ & $e_{0}$ & $w_{\mathrm{L}}$ & $w_{\mathrm{p}}$ & $I_{\mathrm{p}}$ & $I_{\mathrm{L}}$ & $c^{\prime}$ & $\varphi^{\prime}$ & $c_{\mathrm{u}}$ & $K_{0}$ & $K_{20} \times 10^{-5}$ & $C_{\mathrm{v}}$ & $a_{\mathrm{v} 1-2}$ & $E_{\mathrm{s}}$ & $S_{\mathrm{t}}$ \\
\hline $\begin{array}{l}\text { Miscellaneous } \\
\text { fill }\end{array}$ & 22.5 & 2.72 & 18.1 & 14.8 & 73 & 0.837 & 30.4 & 18.5 & 11.9 & 0.34 & - & - & - & - & - & - & 0.33 & 5.6 & - \\
\hline Plain fill & 23.8 & 2.72 & 18.2 & 14.8 & 76 & 0.857 & 32.1 & 19.3 & 12.8 & 0.34 & - & - & 15 & 0.700 & - & - & 0.31 & 6.0 & - \\
\hline Silty clay & 22.5 & 2.72 & 20.1 & 16.4 & 90 & 0.660 & 32.8 & 19.7 & 13.1 & 0.22 & 42 & 29.3 & 23 & 0.586 & 1.40 & 1.92 & 0.23 & 7.2 & 1.5 \\
\hline
\end{tabular}


Table 5. The empirical equation of $K_{0}$ (Hu 1997)

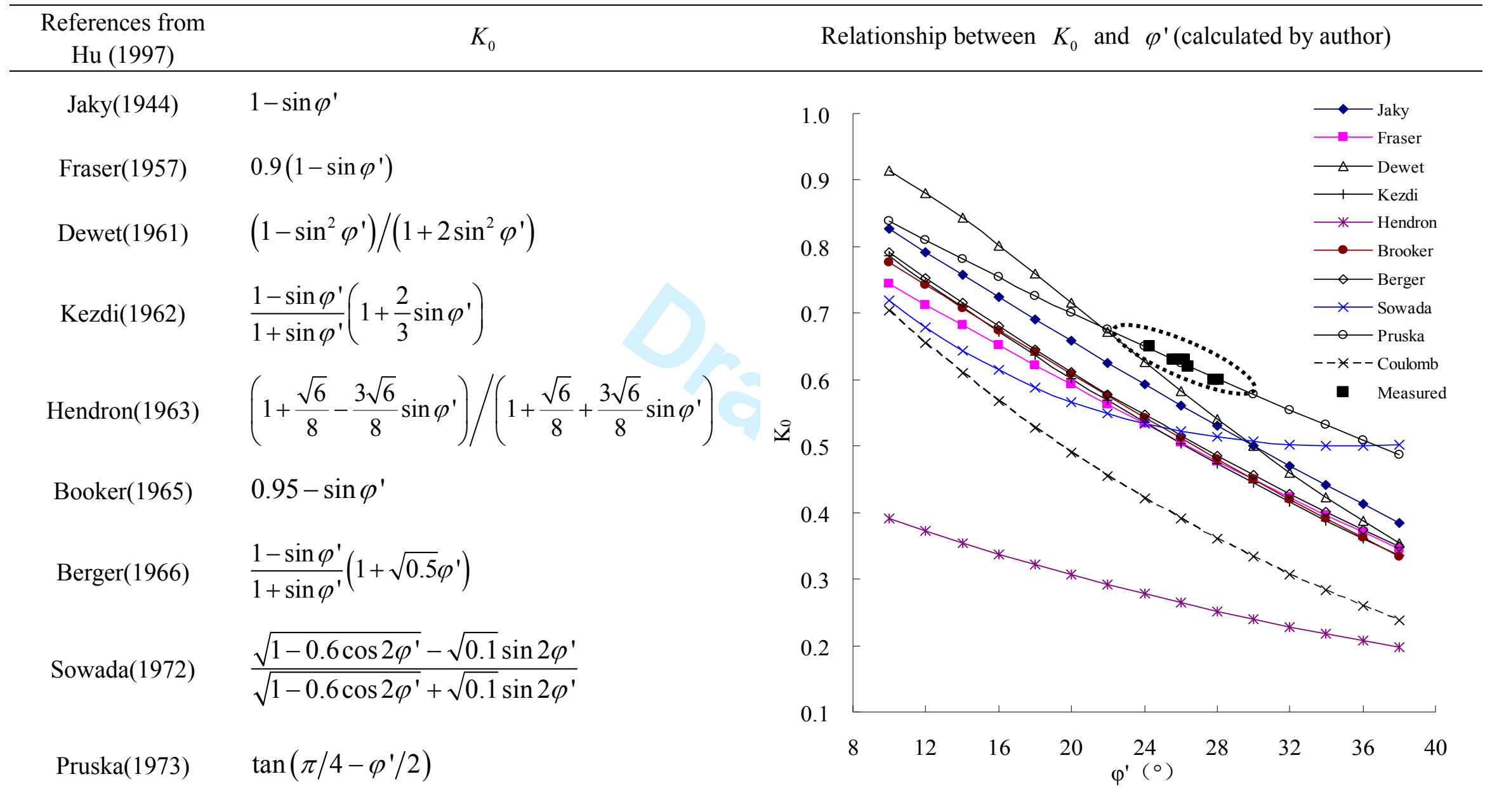


Table 6. Weighted average of physical and mechanics parameters of soils above the tunnel

\begin{tabular}{|c|c|c|c|c|c|c|c|c|c|c|c|c|}
\hline Sections & $\begin{array}{c}E_{\mathrm{u}} \\
(\mathrm{MPa})\end{array}$ & $v_{\mathrm{u}}$ & $v_{0}$ & $\begin{array}{c}c_{\mathrm{u}} \\
(\mathrm{kPa})\end{array}$ & $\begin{array}{c}c^{\prime} \\
(\mathrm{kPa})\end{array}$ & $\varphi^{\prime}\left({ }^{\circ}\right)$ & $\begin{array}{c}\gamma \\
\left(\mathrm{kN} / \mathrm{m}^{3}\right)\end{array}$ & $m_{\mathrm{v}}^{\prime}\left(\mathrm{MP}^{-1}\right)$ & $K_{0}^{\prime}$ & $h_{\mathrm{w}}(\mathrm{m})$ & $\begin{array}{c}P_{\mathrm{v}}^{\prime} K_{0}{ }^{\prime}+P_{\mathrm{w}} \\
(\mathrm{kPa})\end{array}$ & $H(\mathrm{~m})$ \\
\hline $13+290$ & 31.5 & 0.5 & 0.383 & 27.6 & 39.1 & 26.4 & 19.0 & 0.46 & 0.62 & 2.4 & 176.3 & 14.2 \\
\hline $13+353$ & 32.0 & 0.5 & 0.386 & 31.8 & 43.1 & 25.7 & 19.9 & 0.60 & 0.63 & 4.1 & 215.4 & 16.0 \\
\hline $13+371$ & 31.8 & 0.5 & 0.385 & 31.7 & 43.9 & 25.9 & 20.0 & 0.30 & 0.63 & 4.7 & 225.5 & 16.6 \\
\hline $13+401$ & 31.6 & 0.5 & 0.384 & 30.0 & 45.1 & 26.2 & 20.0 & 0.57 & 0.63 & 5.6 & 243.7 & 17.7 \\
\hline $13+460$ & 31.1 & 0.5 & 0.393 & 32.7 & 46.0 & 24.3 & 18.5 & 0.50 & 0.65 & 7.8 & 251.1 & 18.7 \\
\hline $13+680$ & 34.3 & 0.5 & 0.383 & 34.5 & 48.2 & 26.4 & 19.6 & 0.38 & 0.62 & 10.2 & 287.2 & 20.4 \\
\hline $13+734$ & 36.4 & 0.5 & 0.376 & 35.0 & 49.6 & 27.8 & 19.3 & 0.32 & 0.60 & 10.5 & 290.5 & 21.4 \\
\hline $14+211$ & 33.1 & 0.5 & 0.375 & 35.0 & 50.0 & 28.1 & 19.2 & 0.33 & 0.60 & 10.4 & 293.0 & 21.8 \\
\hline $14+230$ & 33.1 & 0.5 & 0.375 & 35.0 & 50.0 & 28.1 & 19.0 & 0.35 & 0.60 & 9.8 & 283.3 & 21.4 \\
\hline $14+290$ & 33.1 & 0.5 & 0.375 & 35.0 & 50.0 & 28.1 & 19.2 & 0.36 & 0.60 & 10.5 & 274.1 & 20.2 \\
\hline $14+310$ & 33.1 & 0.5 & 0.375 & 27.6 & 50.0 & 28.1 & 19.1 & 0.38 & 0.60 & 10.9 & 266.4 & 19.5 \\
\hline
\end{tabular}


Table 7. Surface settlement behaviors of Xi'an Metro

\begin{tabular}{|c|c|c|c|c|c|c|}
\hline Sections & $V_{1}(\%)$ & $\begin{array}{r}g(\mathrm{~mm}) \\
\mathrm{Bc}\end{array}$ & $i(\mathrm{~m})$ & $k=H / i$ & $\begin{array}{l}S_{\max }(\mathrm{mm}) \\
\text { Measured }\end{array}$ & Description \\
\hline $13+290$ & 1.02 & 31.4 & 8.9 & 0.63 & -13.6 & \\
\hline $13+341$ & 3.32 & 101.6 & 9.3 & 0.60 & -42.5 & \\
\hline $13+353$ & 2.91 & 88.9 & 9.2 & 0.58 & -37.5 & Near the Bell Tower \\
\hline $13+371$ & 2.36 & 72.1 & 8.0 & 0.48 & -35.0 & $\bar{k}=0.57$ \\
\hline $13+389$ & 2.85 & 87.1 & 9.1 & 0.53 & -37.2 & \\
\hline $13+401$ & 4.40 & 134.0 & 11.2 & 0.63 & -46.7 & \\
\hline $13+460$ & 1.03 & 31.7 & 9.5 & 0.51 & -13.0 & \\
\hline $13+680$ & 0.83 & 25.5 & 8.0 & 0.39 & -12.3 & Between the Bell \\
\hline $13+734$ & 0.89 & 27.3 & 9.0 & 0.42 & -11.8 & $\begin{array}{l}\text { Tower and the South } \\
\text { gate of the City Wall }\end{array}$ \\
\hline $13+782$ & 1.69 & 51.8 & 6.9 & 0.32 & -29.2 & $\bar{k}=0.37$ \\
\hline $13+849$ & 1.76 & 53.9 & 7.7 & 0.35 & -27.3 & \\
\hline $14+211$ & 0.59 & 18.0 & 11.6 & 0.53 & -6.0 & \\
\hline $14+230$ & 0.50 & 15.3 & 13.2 & 0.62 & -4.5 & Near the City Wall \\
\hline $14+290$ & 0.58 & 17.9 & 11.8 & 0.59 & -5.8 & $\bar{k}=0.58$ \\
\hline $14+310$ & 0.58 & 17.8 & 11.6 & 0.59 & -5.9 & \\
\hline
\end{tabular}

(Where, $\bar{k}$ is the average ratio of the settlement trough width to buried depth of tunnel axis) 
Table 8 Gap due to shield intermittent alignment in different monitoring sections

\begin{tabular}{|c|c|c|c|c|c|c|c|c|}
\hline \multirow{2}{*}{ Sections Results } & \multirow{2}{*}{$\begin{array}{c}P_{\mathrm{i}} \\
(\mathrm{MPa})\end{array}$} & \multirow[t]{2}{*}{$R_{0} / R$} & \multirow{2}{*}{$\begin{array}{c}\text { Lee and } \\
\text { Rowe }(1992) \\
U_{\mathrm{i}}(\mathrm{mm})\end{array}$} & \multicolumn{2}{|c|}{ General stress solution } & \multirow{2}{*}{$\begin{array}{l}\text { Lee and Rowe (1992) } \\
\qquad \begin{array}{c}\left(\mathrm{g}_{2}=8 \sim 16 \mathrm{~mm}\right) \\
\mathrm{g}_{3}=\min \left(U_{\mathrm{i}} / 3,0.6 \mathrm{~g}_{2}\right)\end{array}\end{array}$} & \multicolumn{2}{|c|}{ General stress solution $\left(\mathrm{g}_{2}=8 \sim 16 \mathrm{~mm}\right)$} \\
\hline & & & & $U_{\mathrm{e}}(\mathrm{mm})$ & $U_{\mathrm{e}, \mathrm{p}}(\mathrm{mm})$ & & $\mathrm{g}_{3}=\min \left(U_{\mathrm{e}} / 3,0.6 \mathrm{~g}_{2}\right)$ & $\mathrm{g}_{3}=\min \left(U_{\mathrm{e}, \mathrm{p}} / 4,0.6 \mathrm{~g}_{2}\right)$ \\
\hline $13+290$ & 0.082 & 0.99 & 3.7 & 27.1 & 27.1 & 1.2 & $4.8 \sim 9.1$ & $4.8 \sim 6.7$ \\
\hline $13+341$ & 0.088 & 1.18 & 4.0 & 32.0 & 36.9 & 1.3 & $4.8 \sim 9.6$ & $4.8 \sim 9.2$ \\
\hline $13+353$ & 0.089 & 1.22 & 4.0 & 33.4 & 39.3 & 1.3 & $4.8 \sim 9.6$ & $4.8 \sim 9.6$ \\
\hline $13+371$ & 0.090 & 1.26 & 4.6 & 35.4 & 43.1 & 1.5 & $4.8 \sim 9.6$ & $4.8 \sim 9.6$ \\
\hline $13+389$ & 0.088 & 1.32 & 4.6 & 37.7 & 48.4 & 1.5 & $4.8 \sim 9.6$ & $4.8 \sim 9.6$ \\
\hline $13+401$ & 0.092 & 1.42 & 4.3 & 39.1 & 52.1 & 1.4 & $4.8 \sim 9.6$ & $4.8 \sim 9.6$ \\
\hline $13+460$ & 0.109 & 1.08 & 4.4 & 39.4 & 59.8 & 1.5 & $4.8 \sim 9.6$ & $4.8 \sim 9.6$ \\
\hline $13+680$ & 0.113 & 1.08 & 4.4 & 42.8 & 65.6 & 1.5 & $4.8 \sim 9.6$ & $4.8 \sim 9.6$ \\
\hline $13+734$ & 0.112 & 1.09 & 4.4 & 42.2 & 63.2 & 1.5 & $4.8 \sim 9.6$ & 4.8 9.6 \\
\hline $13+782$ & 0.113 & 1.05 & 4.9 & 45.8 & 65.3 & 1.6 & $4.8 \sim 9.6$ & $4.8 \sim 9.6$ \\
\hline $13+849$ & 0.105 & 1.13 & 4.9 & 47.2 & 68.6 & 1.6 & $4.8 \sim 9.6$ & 4.8 9.6 \\
\hline $14+211$ & 0.125 & 1.02 & 4.9 & 45.8 & 65.4 & 1.6 & $4.8 \sim 9.6$ & $4.8 \sim 9.6$ \\
\hline $14+230$ & 0.125 & 0.98 & 4.9 & 44.3 & 61.6 & 1.6 & $4.8 \sim 9.6$ & 4.8 9.6 \\
\hline $14+290$ & 0.126 & 0.90 & 4.9 & 41.4 & 53.5 & 1.6 & $4.8 \sim 9.6$ & $4.8 \sim 8.2$ \\
\hline $14+310$ & 0.128 & 0.83 & 4.9 & 39.3 & 48.6 & 1.6 & $4.8 \sim 9.6$ & $4.8 \sim 7.0$ \\
\hline
\end{tabular}


Table 9 Components of the total gap parameter in different monitoring sections

\begin{tabular}{|c|c|c|c|c|c|c|c|c|c|c|c|c|c|c|}
\hline Results & & & & & & & & & & & & $g_{\mathrm{t}}(\mathrm{mm}$ & & \\
\hline Sections & $(\mathrm{mm})$ & $g_{21}$ & $g_{2 \mathrm{u}}$ & $g_{31}$ & $g_{3 \mathrm{u}}$ & $g_{41}$ & $g_{4 \mathrm{u}}$ & $g_{51}$ & $g_{5 \mathrm{u}}$ & $g_{6}(\mathrm{~mm})$ & $g_{\mathrm{tl}}$ & $g_{\text {tu }}$ & $g_{\text {tav }}(\mathrm{mm})$ & $\begin{array}{c}\text { Back } \\
\text { analysis }\end{array}$ \\
\hline $13+290$ & 2.7 & 8.0 & 16.0 & 4.8 & 9.1 & 2.8 & 11.0 & 0.0 & 25.0 & 0.0 & 18.3 & 59.5 & 38.9 & 31.4 \\
\hline $13+353$ & 5.9 & 8.0 & 16.0 & 4.8 & 9.6 & 2.8 & 11.0 & 0.0 & 25.0 & 38.4 & 59.9 & 101.1 & 80.5 & 88.9 \\
\hline $13+371$ & 3.2 & 8.0 & 16.0 & 4.8 & 9.6 & 2.8 & 11.0 & 0.0 & 25.0 & 24.7 & 43.5 & 84.7 & 64.1 & 72.1 \\
\hline $13+389$ & 3.5 & 8.0 & 16.0 & 4.8 & 9.6 & 2.8 & 11.0 & 0.0 & 25.0 & 35.9 & 55.0 & 96.2 & 75.6 & 87.1 \\
\hline $13+460$ & 4.0 & 8.0 & 16.0 & 4.8 & 9.6 & 2.8 & 11.0 & 0.0 & 25.0 & 4.1 & 23.7 & 64.9 & 44.3 & 31.7 \\
\hline $13+680$ & 3.5 & 8.0 & 16.0 & 4.8 & 9.6 & 2.8 & 11.0 & 0.0 & 25.0 & 2.9 & 21.9 & 63.1 & 42.5 & 25.5 \\
\hline $13+734$ & 5.6 & 8.0 & 16.0 & 4.8 & 9.6 & 2.8 & 11.0 & 0.0 & 25.0 & 3.6 & 24.8 & 66.0 & 45.4 & 27.3 \\
\hline $13+782$ & 10.3 & 8.0 & 16.0 & 4.8 & 9.6 & 2.8 & 11.0 & 0.0 & 25.0 & 2.4 & 28.3 & 69.5 & 48.9 & 51.8 \\
\hline $13+849$ & 8.8 & 8.0 & 16.0 & 4.8 & 9.6 & 2.8 & 11.0 & 0.0 & 25.0 & 6.2 & 30.6 & 71.8 & 51.2 & 53.9 \\
\hline $14+211$ & 4.8 & 8.0 & 16.0 & 4.8 & 9.6 & 2.8 & 11.0 & 0.0 & 25.0 & 0.7 & 21.1 & 62.3 & $21.1 *$ & 18.0 \\
\hline
\end{tabular}

Note: * represents the lower bound of the gap parameter, because that the monitoring sections from $14+211$ to $14+310$ are adjacent the City Wall, $g_{\mathrm{tl}}$ is the lower bound of the total gap parameter; $g_{\mathrm{tu}}$ is the upper bound of the total gap parameter; $g_{\mathrm{tav}}$ is the average value of the $g_{\mathrm{tl}}$ and $g_{\mathrm{tu}}$, and is equal to $\left(g_{\mathrm{tl}}+g_{\mathrm{tu}}\right) / 2$. 